\title{
Solute carrier family 12 member 2 as a proteomic and histological biomarker of dysplasia and neoplasia in ulcerative colitis
}

\begin{abstract}
Merli, Angela-Maria ; Vieujean, Sophie ; Massot, Charlotte ; Blétard, Noella ; Quesada Calvo, Florence ; Baiwir, Dominique ; Mazzucchelli, Gabriel ; Servais, Laurence ; Wéra, Odile ; Oury, Cécile ; de Leval, Laurence ; Sempoux, Christine ; Manzini, Roberto ; Bluemel, Sena ; Scharl, Michael ; Rogler, Gerhard ; De Pauw, Edwin ; Coimbra Marques, C ; Colard, Arnaud ; Vijverman, Anne ; Delvenne, Philippe ; Louis, Edouard ; Meuwis, Marie-Alice
\end{abstract}

\begin{abstract}
BACKGROUND AND AIMS Ulcerative colitis (UC) patients have a greater risk of developing colorectal cancer through inflammation-dysplasia-carcinoma sequence of transformation. The histopathological diagnosis of dysplasia is therefore of critical clinical relevance, but dysplasia may be difficult to distinguish from inflammatory changes. METHODS A proteomic pilot study on 5 UC colorectal dysplastic patients highlighted proteins differentially distributed between paired dysplastic, inflammatory and normal tissues. The best candidate marker was selected and immunohistochemistry confirmation was performed on AOM/DSS mouse model lesions, 37 UC dysplasia, 14 UC cancers, 23 longstanding UC, 35 sporadic conventional adenomas, 57 sporadic serrated lesions and 82 sporadic colorectal cancers. RESULTS Differential proteomics found 11 proteins significantly more abundant in dysplasia compared to inflammation, including Solute carrier family 12 member 2 (SLC12A2) which was confidently identified with 8 specific peptides and was below the limit of quantitation in both inflammatory and normal colon. SLC12A2 immunohistochemical analysis confirmed the discrimination of preneoplastic and neoplastic lesions from inflammatory lesions in mice, UC and in sporadic contexts. A specific SLC12A2 staining pattern termed "loss of gradient" reached $89 \%$ sensitivity, 95\% specificity and $92 \%$ accuracy for UC-dysplasia diagnosis together with an inter-observer agreement of $95.24 \%$ (multirater $\kappa$ free of 0.90 ; IC95\%: $0.78-1.00$ ). Such discrimination could not be obtained by Ki67 staining. This specific pattern was also associated with sporadic colorectal adenomas and cancers. CONCLUSIONS We found a specific SLC12A2 immunohistochemical staining pattern in precancerous and cancerous colonic UC-lesions which could be helpful for diagnosing dysplasia and cancer in UC and non-UC patients.
\end{abstract}

DOI: https://doi.org/10.1093/ecco-jcc/jjaa168

Posted at the Zurich Open Repository and Archive, University of Zurich ZORA URL: https://doi.org/10.5167/uzh-190594

Journal Article

Accepted Version

Originally published at:

Merli, Angela-Maria; Vieujean, Sophie; Massot, Charlotte; Blétard, Noella; Quesada Calvo, Florence; Baiwir, Dominique; Mazzucchelli, Gabriel; Servais, Laurence; Wéra, Odile; Oury, Cécile; de Leval, Laurence; Sempoux, Christine; Manzini, Roberto; Bluemel, Sena; Scharl, Michael; Rogler, Gerhard; De Pauw, Edwin; Coimbra Marques, C; Colard, Arnaud; Vijverman, Anne; Delvenne, Philippe; Louis, Edouard; Meuwis, Marie-Alice (2021). 
Solute carrier family 12 member 2 as a proteomic and histological biomarker of dysplasia and neoplasia in ulcerative colitis. Journal of Crohn's Colitis, 15(2):287-298.

DOI: https://doi.org/10.1093/ecco-jcc/jjaa168 
Solute carrier family 12 member 2 as a proteomic and histological biomarker of dysplasia and neoplasia in ulcerative colitis

Angela-Maria Merli ${ }^{\mathrm{a}}$, Sophie Vieujean ${ }^{\mathrm{a}, \mathrm{b}}$, Charlotte Massot $^{\mathrm{a}, \mathrm{b}}$, Noella Blétard ${ }^{\mathrm{c}}$, Florence Quesada Calvo $^{\mathrm{a}}$, Dominique Baiwir ${ }^{\mathrm{d}}$, Gabriel Mazzucchelli ${ }^{\mathrm{e}}$, Laurence Servais ${ }^{\mathrm{f}}$, Odile Wéra ${ }^{\mathrm{f}}$, Cécile Oury ${ }^{\mathrm{f}}$, Laurence de Leval $^{\mathrm{g}}$, Christine Sempoux ${ }^{\mathrm{g}}$, Roberto Manzini ${ }^{\mathrm{h}}$, Sena Bluemel ${ }^{\mathrm{h}}$, Michael Scharl ${ }^{\mathrm{h}}$, Gerhard Rogler $^{\mathrm{h}}$, Edwin De Pauw ${ }^{\mathrm{e}}$, C. Coimbra Marques ${ }^{\mathrm{i}}$, Arnaud Colard ${ }^{\mathrm{j}}$, Anne Vijverman ${ }^{\mathrm{k}}$, Philippe Delvenne $^{\mathrm{c}}$, Edouard Louis ${ }^{\mathrm{a}, \mathrm{b} \$}$, Marie-Alice Meuwis ${ }^{\mathrm{a}, \mathrm{b} \$}$

${ }^{\mathrm{a}}$ Laboratory of Translational Gastroenterology, University of Liège, Liège, Belgium. ${ }^{\mathrm{b}}$ HepatoGastroenterology and Digestive Oncology, University Hospital CHU of Liège, Liège, Belgium. ${ }^{\mathrm{c}}$ Pathological Anatomy and Cytology, University Hospital CHU of Liège, Liège, Belgium. ${ }^{\mathrm{d}}$ GIGA Proteomics Facility, University of Liège, Liège, Belgium. ${ }^{\mathrm{e}}$ Laboratory of Mass Spectrometry, University of Liège, Liège, Belgium. ${ }^{\mathrm{f}}$ Laboratory of Cardiology, GIGA-Cardiovascular Sciences, University of Liège, Liège, Belgium. ${ }^{\mathrm{g}}$ Institute of Pathology, Centre Hospitalier Universitaire Vaudois, University of Lausanne, Lausanne, Switzerland. ${ }^{\mathrm{h}}$ Department of Gastroenterology and Hepatology, University Hospital Zurich, University of Zurich, Zurich, Switzerland. 'Abdominal Surgery Department, University Hospital $\mathrm{CHU}$ of Liège, Liège, Belgium. ${ }^{\mathrm{j}}$ Department of Gastroenterology, CHC Clinique Saint-Joseph, Liège, Belgium. ${ }^{k}$ Department of Gastroenterology, CHR Citadelle, Liège, Belgium. ${ }^{\$}$ Equally contributed to this work

Address for correspondence: Angela-Maria Merli, Laboratory of Translational Gastroenterology, University of Liège, GIGA-Research, +2, B34, Avenue de l'hôpital 1, 4000 Liège, Belgium. Tel: +324-3663428; Fax: +32-4-3667889; e-mail: am.merli@uliege.be 
Abbreviations: ADC, Adenocarcinoma; AOM, Azoxymethane; CAC, colitis-associated cancer; CD, Crohn's disease; CRC, colorectal cancer; DAI, Dysplasia associated to inflammation; DSp, Dysplasia developed on inflammation-free mucosa; DSS, Dextran sulfate sodium; EDTA, Ethylenediaminetetracetic acid; FFPE, Formalin-fixed paraffin-embedded; GI, Gastrointestinal; H\&E, Hematoxylin and eosin; HGA, High-grade adenoma; HGD, High-grade dysplasia; HPP, Hyperplastic polyp; I, Inflammatory; IBD, Inflammatory bowel disease; IC, Confidence interval; IHC, Immunohistochemistry; LCM, Laser-capture microdissection; LFQ, Label free quantification; LGA, Low-grade adenoma; LGD, Low-grade dysplasia; N, Normal; OA, Overall agreement; PBS, Phosphate buffer saline; SLC12A2, Solute carrier family 12 member 2; SSA/P, Sessile serrated adenoma/polyp; TSA, Traditional serrated adenoma; UC, ulcerative colitis; UPLC, Ultra-performance liquid chromatography

\section{Conference presentation}

Belgian Week of Gastroenterology, Antwerp 2017

Belgian Week of Gastroenterology, Antwerp 2018

European Crohn's and Colitis Congress, Vienna 2018

Belgian Week of Gastroenterology, Antwerp 2020 


\begin{abstract}
Background and Aims: Ulcerative colitis (UC) patients have a greater risk of developing colorectal cancer through inflammation-dysplasia-carcinoma sequence of transformation. The histopathological diagnosis of dysplasia is therefore of critical clinical relevance, but dysplasia may be difficult to distinguish from inflammatory changes.
\end{abstract}

Methods: A proteomic pilot study on 5 UC colorectal dysplastic patients highlighted proteins differentially distributed between paired dysplastic, inflammatory and normal tissues. The best candidate marker was selected and immunohistochemistry confirmation was performed on AOM/DSS mouse model lesions, 37 UC dysplasia, 14 UC cancers, 23 longstanding UC, 35 sporadic conventional adenomas, 57 sporadic serrated lesions and 82 sporadic colorectal cancers.

Results: Differential proteomics found 11 proteins significantly more abundant in dysplasia compared to inflammation, including Solute carrier family 12 member 2 (SLC12A2) which was confidently identified with 8 specific peptides and was below the limit of quantitation in both inflammatory and normal colon. SLC12A2 immunohistochemical analysis confirmed the discrimination of preneoplastic and neoplastic lesions from inflammatory lesions in mice, UC and in sporadic contexts. A specific SLC12A2 staining pattern termed "loss of gradient" reached $89 \%$ sensitivity, $95 \%$ specificity and 92\% accuracy for UC-dysplasia diagnosis together with an inter-observer agreement of $95.24 \%$ (multirater $\kappa_{\text {free }}$ of 0.90 ; IC95\%: $0.78-1.00$ ). Such discrimination could not be obtained by Ki67 staining. This specific pattern was also associated with sporadic colorectal adenomas and cancers.

Conclusions: We found a specific SLC12A2 immunohistochemical staining pattern in precancerous and cancerous colonic UC-lesions which could be helpful for diagnosing dysplasia and cancer in UC and non-UC patients.

Keywords: SLC12A2, dysplasia associated to inflammation, colorectal neoplasia 


\section{Introduction}

Chronic inflammation is known to be linked with cancer development, like in inflammatory bowel diseases (IBD). Patients suffering from IBD, such as ulcerative colitis (UC) and Crohn's disease (CD), are at risk of developing colorectal cancer (CRC) in areas affected by chronic inflammation, namely colitis-associated cancer (CAC). ${ }^{1}$ In the last decades, the risk of CAC in UC patients has decreased, mainly due to a better control of chronic inflammation, and to more effective surveillance programs including high resolution endoscopy and chromoendoscopy. ${ }^{2,3}$ Despite these advances, CAC remains a clinical problem. IBD patients show a 5\% cumulative risk of CAC after more than 20 years of disease duration, and this risk is even higher with additional presence of extensive disease, primary sclerosing cholangitis and if the disease occurred at a young age. ${ }^{4,5} \mathrm{~A}$ recent meta-analysis concluded that suffering from UC increases the risk of colorectal cancer by 2.4 -fold compared to the general population. ${ }^{6}$

CAC develops following the sequence of transformation "inflammation-dysplasia-adenocarcinoma"? Chronic inflammation leads to oxidative stress-induced DNA damages in colonic epithelium, which induce the activation of pro-carcinogenic and silencing of tumour suppressor genes. ${ }^{8,9}$ All these events lead to epithelial dysplasia. ${ }^{10}$ Most of the key regulator genes (e.g. TP53 and APC) involved in the CRC development are also found in the inflammation-associated dysplasia and CAC development, but their sequence of mutation, their frequency and occurrences differ in CAC from CRC. ${ }^{9,11}$

Identification of colonic dysplasia is essential for IBD patient surveillance. However, before 2015, endoscopic classification of dysplasia was confusing. This led to the establishment of the SCENIC International Consensus Statement on surveillance and management of dysplasia in IBD. ${ }^{12}$ To provide recommendations for diagnosis and surveillance, SCENIC standardized the terminology of endoscopic dysplastic lesions, adapted from the Paris classification. ${ }^{13}$ However, ongoing histological inflammation, which is often observed even in patients reporting clinical remission, makes the histopathological confirmation of dysplasia particularly difficult. Indeed, regenerative epithelium found in inflammatory areas shares features with dysplasia, including nuclear enlargement, hyperchromasia, stratification and an increased number of mitoses, leading to a diagnosis of indefinite for dysplasia. ${ }^{14}$

The aim of our study was to highlight potential protein markers able to discriminate early dysplasia from inflammation and normal colon. We therefore performed a pilot proteomic study using lasercapture microdissection (LCM) and 2D nano-UPLC-MS/MS on colonic low-grade dysplasia in UC. The best biomarker candidate was confirmed by immunohistochemistry (IHC) on Azoxymethane/Dextran sulfate sodium (AOM/DSS) colon tissues and on an independent panel of human colorectal lesions from UC and non-IBD patients. 


\section{Methods}

Patient inclusions, clinical information and tissues samples

Human formalin-fixed paraffin-embedded (FFPE) colorectal tissues were obtained from several biobanks hospitals after approvals of their ethical reviewing boards: University Hospital CHU Liège (ref: 2015-144), the Centre Hospitalier Régional de la Citadelle CHR Liège (ref: 16/14/802), Centre Hospitalier Chrétien CHC Liège (ref: FD/bl/1578 - B412201628406), University Hospital of Zurich (ref: KEK ZH 2018-02193) and the Centre Hospitalier Universitaire Vaudois (ref: CER-VD 201900082).

For the proteomic study, we retrospectively (from 2008 to 2015) selected 98 UC patients with confirmed colorectal dysplasia developed in inflammatory areas (dysplasia associated to inflammation, DAI) at CHU Liège. Exclusion criteria were: previous or concomitant cancer and inherited disorders increasing the risk of colorectal cancer (Lynch syndrome and familial adenomatous polyposis). To confirm the dysplastic, inflamed or normal aspect of the available tissues, haematoxylin and eosin (H\&E) stained sections were reviewed by an expert gastrointestinal (GI) pathologist (N.B.). This review was based on the European Crohn's and Colitis Organisation (ECCO) guidelines for histopathology in IBD and the Surveillance for Colorectal Endoscopic Neoplasia detection and management in inflammatory bowel disease patients: International Consensus recommendations (SCENIC) criteria. ${ }^{12,15}$ Due to the limited amount of material available, the requirements of the downstream technical hints of sample preparation for differential proteomic analysis, we finally selected 5 UC patients with polypoid low-grade dysplasia associated to UC (UCDAI) also providing available tissues with either inflammation (UC-I) or without any alteration and defined as normal (UC-N) (Table 1). These 3 tissue types originating from the same 5 patients were therefore qualified as paired samples.

For the IHC studies, we included 74 UC patients. Table 1 details the clinical information of these patients showing different lesions types : 28 UC-DAI cases (including the five cases studied by proteomics) with matched UC-I $(n=21)$ and/or UC-N (n=9) tissues when available; 9 UC with dysplasia developed on inflammation-free mucosa (UC-DSp) and matched normal paired tissues UC$\mathrm{N}(n=6) ; 14$ colitis associated colorectal cancer tissues (UC-CAC) with paired inflammatory tissues UC-I $(n=8)$ and/or normal UC-N ( $n=11)$ when available; 23 longstanding UC patients (patients with $\geq$ 10 years disease duration who did not developed dysplasia, all previous colonoscopies or colectomies where negative for dysplasia and cancer) ${ }^{16,17}$ with UC-I $(n=23)$ and paired UC-N $(n=15)$ tissues.

Table 2 summarizes the clinical information of 18 non-IBD controls (normal margin of diverticulitis specimen) and 174 patients with sporadic precancerous or cancerous lesions: conventional low-grade adenomas (LGA) ( $n=19)$, high-grade adenomas (HGA) ( $n=16)$, sessile serrated adenomas/polyps (SSA/P) ( $n=19)$, traditional serrated adenomas (TSA) $(n=19)$, hyperplastic polyps (HPP) $(n=19)$, and sporadic colorectal cancers pT1 $(n=19)$, pT2 $(n=22)$, pT3 $(n=22)$ and pT4 $(n=19)$, all reviewed by our GI pathologist (N.B.) according to standardized guidelines and the American Joint Committee on Cancer (AJCC) Cancer Staging Manual. ${ }^{18}$ When accessible, we characterized the normal tissues directly adjacent to the cancerous lesions (the normal tissue surrounding the cancer on the same specimen section) with respectively pT1-adjacent $(n=12)$, pT2-adjacent $(n=16)$, pT3-adjacent $(n=9)$ and pT4-adjacent $(n=9)$ and the normal paired tissues taken at the surgical margin : pT1-margin $(n=8)$, pT2-margin $(n=10)$, pT3-margin $(n=12)$ and pT4-margin $(n=8)$.

AOM/DSS mouse model samples 
Colon tissues of AOM/DSS ${ }^{19}$ or DSS mice were obtained thanks to a collaboration with Dr. Oury's laboratory, GIGA-Cardiovascular Sciences, ULiège (C.O., L.S. and O.W.). The mouse study was approved by the Committee on the Ethics of Animal Experiments of the University of Liège (permit no.1220).

In the AOM/DSS model, 5-week old C57Bl/6J mice (JAX ${ }^{\mathrm{TM}}$ Mice Strain) (Charles River, France) were injected once intraperitoneally $(12 \mathrm{mg} / \mathrm{kg}$ ) with AOM carcinogen (Sigma-Aldrich, Saint Louis, USA) diluted in phosphate buffer saline (PBS) before receiving three cycles of DSS (2\%) (45 kDa; TdB Consultancy, Uppsala, Sweden) via drinking water for 5 days, followed by 16 days of regular water. Mice were euthanized at day 15, 29, 34, 50, 55, 65, 70, 80 and 120. In the chronic inflammation model, mice were treated with DSS (3\%) for 5 days followed by 21 days of regular water. ${ }^{20}$ The acute inflammation model was induced by treatment with DSS (5\%) for 6 days. Control mice only received PBS and were euthanized at day 90. A total of 81 mice were studied. Colons were collected and FFPE as previously described. ${ }^{21}$ The GI pathologist (N.B.) reviewed each H\&E stained sections to identify all lesions such as inflammation, dysplasia or adenocarcinoma with characterisation of stage and morphology (see supplementary Table 1 for details). The number of tissues analysed per lesion types are as follows: low-grade dysplasia (LGD) $(n=51)$ and paired inflammatory tissues (I-LGD), high-grade dysplasia (HGD) $(n=35)$ and paired inflammatory tissues (I-HGD), adenocarcinoma (ADC) $(n=38)$ and paired inflammatory tissues (I-ADC), inflammatory tissues (I) $(n=20)$ and normal tissues (PBS) ( $n=12)$.

Label free proteomic study

Sample preparation and proteomics by LC-MS/MS

Before the proteomic analysis, we performed laser capture microdissection for epithelial cell enrichment. We collected a total of 5000 epithelial cells per tissue type on $5 \mu \mathrm{m}$ tissue sections using a Leica LMD 7000 (Leica Microsystems, Wetzlar, Germany) according to the manufacturer instructions (see Supplementary data for details).

The 15 samples were all processed using a specific antigen retrieval and double trypsin digestion protocol previously described. ${ }^{22}$

Peptide digests separation was achieved by reverse-phase liquid chromatography using a 2 dimensions (2D) ultra-performance liquid chromatography (UPLC) on a nanoAcquity instrument (Waters, Milford, USA) as detailed previously. ${ }^{22}$ A 2D nano-UPLC coupled to a Thermo Scientific Q Exactive Plus Hybrid Quadrupole-orbitrap mass spectrometer (Thermo Fisher Scientific, Waltham, USA) equipped with a nanospray ESI source operated in positive mode was used as detailed in Supplementary data.

\section{Protein identifications and differential analysis}

The analysis of the raw spectra was performed using MaxQuant 1.5.2.8. for the protein identifications and Label free quantification (LFQ) (see Supplementary data for search parameters). ${ }^{23}$ Raw data files have been deposited to the ProteomeXchange Consortium via the PRIDE $^{24}$ partner repository (http://proteomecentral.proteomexchange.org, identifier PXD018679).

We used Perseus 1.5.5.0 for differential analysis with Log2 transformed LFQ values. ${ }^{25}$ We applied a one-way ANOVA test to compare the three groups and a paired Student t test to compare groups two by two. Results were considered significant when $\mathrm{p} \leq 0.05$. Proteins were considered as "only" 
belonging to on group when a LFQ value was available in 5 replicates out of 5 for one group and no LFQ value was available in 5 out of 5 replicates for the other group; meaning that the protein was significantly identified but below the limit of quantification of the technique in this specific experimental and instrumental setup.

Immunohistochemistry experiments

\section{IHC sample preparation}

FFPE tissue sections were treated as previously described. ${ }^{26}$ Tissue sections were incubated $1 \mathrm{~h}$ at room temperature with primary antibodies: polyclonal Anti-SLC12A2 antibody HPA020130 (SigmaAldrich, Saint Louis USA) used at 1/2000 for human tissues and polyclonal Anti-NKCC1 antibody ab59791 (Abcam, Cambridge, United Kingdom) used at 1/1000 for mouse tissues; Ki67 antibody [SP6] (Abcam, Cambridge, United Kingdom) at 1/200 dilution. Absence of primary antibody was used as negative control conditions.

\section{IHC characterisation}

Three independent scorers (A.-M. M., C. M. and M.-A. M.) not trained in pathology and without prior knowledge of clinical data, evaluated the IHC sections. SLC12A2 IHC characterization was established according to two parameters. First, the staining pattern was qualified as "gradient" or "loss of gradient". The gradient was defined as a decreasing staining intensity from the base bottom of the crypts to the surface epithelium. The loss of gradient was established when the gradient could not be observed (showing either heterogeneous staining or homogenous staining along the crypt and surface epithelium) (see Figures 2C.1, 2C.2 and 2C.5 for gradient pattern, and 2C.4 and 2C.6 for the loss of gradient pattern illustrations). In case of conflicting results between the scorers, the final consensus after discussion or the minimum agreement of 2 out of the 3 scorers was taken as final results. Second, a semi-quantitative evaluation of the staining intensity was made according to the estimation of the percentage of the stained cells and the signal intensity in these positive cells ranging from 0 to 4: $0=$ no staining, $1=$ weak, $2=$ medium, $3=$ strong, $4=$ very strong. Practically, due to the existence of a gradient between surface and crypt epithelium in some samples, the staining intensity score was obtained by the averaged value of the scores of the surface epithelium and the base bottom of the crypts. The final staining score of the tissue lesion was obtained based on the mean of the 3 scorers.

The Ki67 IHC was performed on some UC-DAI cases with available tissue ( $n=14)$. Positive nuclei were counted. The Ki67 IHC sections were scanned using Hamamatsu Photonics K.K. (Hamamatsu Photonics Europe GmbH, Herrsching, Germany) (magnification 40X) and uploaded on QuPath 0.1.2 (Queen's University, Belfast, Northern Ireland) for cellular count. Counts established on four fields for each lesion or tissue type were analysed and averaged.

\section{IHC data analysis}

We used GraphPad Prism 7.00 (GraphPad Software, La Jolla, USA) for statistical analyses of IHC results. Kruskal-Wallis test was applied to compare SLC12A2 staining intensity score in all groups. Wilcoxon paired or Mann-Whitney unpaired tests were applied when appropriated to compare groups 2 by 2 .

We applied Chi-squared test to compare all groups and Fisher's exact test for 2 by 2 comparisons for the SLC12A2 staining pattern human analysis. 
The one-way ANOVA test was used to compare the percentage of Ki67 positive cells in all groups. Tukey's post-hoc test was applied to compare groups 2 by 2. Pearson $r$ correlation test was applied to analyse the correlation between SLC12A2 staining intensity score and the percentage of Ki67 positive cells. Chi-square or Fisher's exact tests were applied when appropriate to test the association of SLC12A2 staining pattern with different Ki67 staining categories as previously reported (based on specific percentages or the median) or by percentiles P25, P33, P66 and P75. ${ }^{27,28}$ 
Staining pattern diagnosis power evaluation

We investigated the discrimination of precancerous and cancerous tissues from normal and inflammatory ones using the SLC12A2 staining pattern with the loss of gradient as discriminating positive parameter. We evaluated the number of patients correctly classified evaluating the sensitivity, specificity and accuracy in the UC and the sporadic contexts. Inter-observer overall agreement (OA) was assessed by the free-marginal multirater kappa (multirater $\kappa_{\text {free }}$ ) based on the results if the three scorers. ${ }^{29}$ 


\section{Results}

Proteomic study

A total of 1070 proteins were identified and 982 were quantified through all samples. Among these, 438 proteins were quantified in minimum 3 out of 5 replicates in at least one group. When comparing UC-DAI and UC-I, 11 proteins were significantly differentially distributed and all of them were more abundant in dysplasia, with 6 of which were found below the limit of quantitation in UC-I sample and termed "UC-DAI only" (Table 3). When comparing UC-DAI and UC-N, 14 proteins were significantly differentially distributed: one was higher in UC-N, 10 were more abundant in UC-DAI and 3 were only quantified in UC-DAI (UC-DAI only) (Table 3). When comparing UC-I and UC-N, 18 proteins were significantly differentially distributed, 10 were more abundant in UC-I, 7 were higher in UC-N and 1 was below the limit of quantification in UC-I and termed "UC-N only" (see Table 3). We selected Solute carrier family 12 member 2 (SLC12A2) for further confirmations as it was the only protein found as "UC-DAI only" in both UC-DAI versus UC-I and UC-DAI versus UC$\mathrm{N}$ comparisons. SLC12A2 was therefore the best candidate for discrimination of UC-DAI from UC-I and UC-N. SLC12A2 was confidently identified with 8 peptides, all of them were unique to this protein and enabled a sequence coverage of $11.3 \%$. No other protein of the same family with similar sequence and with unique peptide showed significant results in the differential analyses performed.

Immunohistochemistry confirmation

In both mouse and human colorectal tissues, SLC12A2 staining was only observed in epithelial cells and not in the extracellular matrix or in the lamina propria. The staining was largely diffuse in the cytoplasm and also positive in the membrane and in the nucleus.

SLC12A2 IHC staining discriminates dysplasia and adenocarcinoma from inflammation in AOM/DSS mice

Staining pattern frequency was differentially distributed across colonic tissue types, with the specific loss of gradient pattern being associated to dysplasia and cancer when compared to their surrounding inflammatory tissues or to normal control tissues $(p \leq 0.0001)$. This was also the case when comparing dysplasia and cancer to inflammatory colonic tissues $(p=0.0028,<0.0001$ and 0.0010 , for LGD, HGD and ADC respectively) (Figure 1A). Moreover, precancerous and cancerous lesions showed a significant higher staining intensity score than their surrounding inflamed tissues (LGD versus I-LGD, HGD versus I-HGD and ADC versus I-ADC, $p<0.0001$ each). This was also observed when comparing LGD, HGD or ADC to inflammatory colonic tissues ( $p<0.0001$ each) or controls ( $p$ $=0.0017,0.0001$ and $<0.0001$ for LGD, HGD and ADC respectively) (Figure 1B).

\section{SLC12A2 IHC staining discriminates UC-dysplasia and cancer from inflammation and normal tissues}

Representative pictures of SLC12A2 IHC distributions are presented for UC-N, UC-I and UC-DAI (Figures 2C.1, 2C.2 and 2C.3 respectively). For UC-DAI patients, SLC12A2 staining pattern frequency was differentially distributed across colonic tissue types, with the loss of gradient pattern being associated to UC-DAI when compared to UC-I and UC-N $(p<0.0001$ and $=0.0003)$. SLC12A2 staining intensity showed a significant differential distribution with UC-DAI $>$ UC-I $(p=0.0063)$ and with UC-DAI > UC-N ( $p=0.0156)$ (Figure 2B). SLC12A2 did not discriminate UC-I from UC-N when considering either the staining pattern or the intensity score (Figure $2 \mathrm{~A}$ and $2 \mathrm{~B}$ ). 
For UC-DSp patients, SLC12A2 staining pattern frequency was also differentially distributed across colonic tissue types: the loss of gradient was associated to UC-DSp when compared to UC-N ( $p=$ 0.0002) (Figure 3A) and Figures 3C.1 and 3C.2 for representative pictures. However, SLC12A2 staining intensity score in dysplasia showed no difference to normal tissues (Figure 3B).

SLC12A2 was also able to discriminate UC colitis-associated cancers from other colonic tissues, as its staining pattern frequency was differentially distributed across the tissues, with the loss of gradient being associated to UC-CAC compared to UC-I and UC-N ( $p<0.0001$ each) (Figure 4A). For SLC12A2 staining intensity score parameter, no difference between UC-CAC and the other tissues could be observed (Figure 4B) and Figures 4C.1, 4C.2 and 4C.3 for representative pictures. Moreover, no statistical difference in staining pattern or intensity score was obtained between UC-I and UC-N.

As the SLC12A2 loss of gradient pattern seemed to be specific of colorectal dysplasia and cancer in UC patients, we tested this pattern in inflamed and normal colon from longstanding UC patients. No significant difference in SLC12A2 staining pattern frequency distribution could be observed between longstanding UC-I and UC-N; neither when comparing frequency distribution of these tissues to inflammatory or normal colonic tissues originating from UC-DAI, DSp or CAC patients (Figure 5A) and Figure 5B.1 and 5B.2 for representative pictures.

\section{SLC12A2, but not Ki67 is able to discriminate UC-dysplasia from inflammation}

Ki67 immunohistochemical staining did not discriminate dysplasia from inflamed and normal colonic tissues originating from the same patients, as a progressive increase in number of positive cells could be observed from UC-N to UC-DAI, but without reaching significance ( $p=0.8600$ for UC-DAI versus UC-I, $p=0.2434$ for UC-DAI versus UC-N and $p=0.5020$ for UC-I versus UC-N, see supplementary Table 2 for IHC data).

No significant association could be observed between the percentages of Ki67 positive cells aggregated by categories of percentages or percentiles and the SLC12A2 staining pattern. Moreover, no significant correlation between the percentage of Ki67 positive cells and SLC12A2 staining intensity score could be obtained $(p=0.5685)$.

SLC12A2 IHC staining discriminates colorectal precancerous and cancerous non-UC lesions from normal tissues

Except SSA/P, all non-IBD precancerous and cancerous colorectal lesions showed more frequently the SLC12A2 loss of gradient pattern than the normal colonic tissues (see Supplementary Figures 1A and 1C). SLC12A2 staining intensity score was significantly higher in conventional colorectal LGA and HGA compared to normal colonic tissues and colorectal serrated lesions (Supplementary Figures $1 \mathrm{~B}$ and $1 \mathrm{C}$ ). Neither the pattern nor the intensity score was able to discriminate LGA from HGA (Supplementary Figure 1B and 1C) and Supplementary Figures 1D.1 to 1D.9 for representative pictures.

In non-IBD cancerous colorectal lesions, the loss of gradient was significantly more frequent in cancerous than in normal colonic tissues (adjacent or taken at surgical margin) (Supplementary Figure 2A). The staining intensity scores were significantly higher in cancer than in the normal colonic tissues (adjacent or taken at surgical margin) (Supplementary Figure 2B). Despite a trend for increase between normal colonic tissues taken at the surgical margin and adjacent to the tumour, no statistical difference could be obtained for any pT stages (Supplementary Figures 2C.1 to 2C.6 for representative pictures). 
SLC12A2 staining pattern as criteria for the discrimination of precancerous and cancerous colorectal lesions

The inter-observer agreement results for SLC12A2 staining pattern assessment between the 3 scorers can be found in Table 4, which summarises the overall agreement (OA), the multirater $\kappa_{\text {free }}$ and the 95\% confidence interval (IC) results. For UC-DAI patients, the OA reached $93.10 \%$ with multirater кfree of 0.86 (IC95\%: $0.76-0.97$ ) and for UC-DAI lesions, OA reached $95.24 \%$ with multirater $\kappa$ free of 0.90 (IC95\%: $0.78-1.00$ ).

Table 5 summarises the percentages of sensitivity, specificity and accuracy obtained for each analysis. The specific staining pattern taken as criteria was able to discriminate tissue types with at least $83 \%$ of sensitivity, $83 \%$ of specificity and $86 \%$ accuracy. The discrimination of UC-DAI from the associated UC-I tissues reached $89 \%$ sensitivity and $95 \%$ specificity, with an accuracy of $92 \%$. Of note, we could not observe any statistical difference regarding the number of false positive or false negative between samples originating from different biobanks. 


\section{Discussion}

The diagnosis of colitis-associated dysplasia and especially of low-grade dysplasia based on $\mathrm{H} \& \mathrm{E}$ stained section remains difficult as a significant degree of inter-observer variability has been demonstrated even between expert GI pathologists. ${ }^{30}$ Hence, confirmation ef the diagnesis by a second pathologist is recommended. ${ }^{12,31}$ These evidences support the need for histological markers to facilitate the diagnosis of dysplasia. In this context Hence, our proteomic pilot study revealed for the first time a differential distribution of SLC12A2 in colorectal dysplasia compared to inflammatory and normal colonic tissues originating from the same UC patients. This was further confirmed by IHC, with SLC12A2 showing a specific loss of gradient staining pattern in colitis-associated dysplasia and cancer. The interobserver OA for SLC12A2 pattern assessment in UC-DAI lesions reached 95.24\% with multirater kfree of 0.90 (IC95\%: $0.78 \quad 1.00$ ) almost perfect agreement and was able to discriminate UC-DAI from their associated UC-I tissues with 89\% sensitivity and 95\% specificity, with an aceuracy of $92 \%$ with high sensitivity, specificity and accuracy. Furthermore, for In non-UC patients, SLC12A2 staining pattern was also able to discriminate conventional colorectal adenomas and cancers at any $\mathrm{pT}$ stages from normal colonic tissues.

SLC12A2, is also known as $\mathrm{Na}^{+}, \mathrm{K}+, 2 \mathrm{Cl}$ cotransporter 1 (NKCC1) or as Bumetanide-sensitive sodium-(potassium)-chloride cotransporter 2 (BSC2), and is a sodium, potassium and chloride electroneutral co-transporter across the plasma membrane. SLC12A2 is expressed in many cell types including polarised secretory epithelia such as lacrimal glands and intestine, and is implicated in fluid secretion. ${ }^{32-35}$ There are two isoforms of SLC12A2 resulting from an alternative splicing of exon $21^{36}$ and sharing $98.68 \%$ of identity. Taken the sequences of the unique peptides observed in our proteomic results and the specificity of the antibody used for IHC, both variants could be upregulated in precancerous and cancerous colorectal lesions. Their potential posttranslational modifications are possible despite not observed in our data. ${ }^{37,38}$ However, in the CRC cell line HT29, the long transcript variant of SLC12A2 was found 14.9 times more abundant then the short form. ${ }^{39}$ A specific study should address these aspects using appropriate technology to decipher the potential role of SLC12A2 variants in the colorectal cancer pathophysiology using statistically relevant number of individual human samples.

To our knowledge, differential proteomics in UC neoplastic progression has been addressed in two previous studies aiming at identifying markers to predict and detect UC-associated dysplasia/cancer and to highlight biological processes involved in CAC progression. ${ }^{40,41}$ Brentnall $\mathrm{T}$. et al. applied an iTRAQ-based quantitative proteomic analysis of epithelial cells isolated by ethylenediaminetetraacetic acid (EDTA) shake-off from 5 fresh frozen colonic tissues where highlighted 98 proteins differentially distributed between non dysplastic tissues from UC-patients and normal tisstues from non IBD-controls, of which only 4 of these proteins (encoded by S10016, P4HB, PDIA 3 and F (GBP) were also found differentially distributed significant in our dataset. May D. et al. used a label free quantitative proteomic analysis of epithelial cells isolated by EDT A shake off from 5 fresh frozen colonic tissues where identified 273 proteins were differentially distributed between nondysplastic tissues from UC patients with and without dysplasia. Only 17 were also found differentially distributed in our dataset, with 3 proteins upregulated in our stuly (encoded by CLCA1, CYCS and CLTC genes) while downregulated in May et al. The authors only provided the lists of proteins with ratio ( $\leq 0.5$ or $\geq 2.0$ ) with no raw data accessible in public repository, making impossible the comparison of SLC12A2 and other significant proteins distributions between studies. Only few of these significant proteins were also found in our study. Obvious differences in techniques and strategy including nature of samples (FFPE $v s$. fresh frozen) and experimental instrument systems might explain these discrepancies. The EDTA-shake off technique provides over $90 \%$ purity in epithelial 
eells with $10 \%$ of remaining cells likely contributing to background signal. CAC arises from early dysplastic lesions located in small tissue areas, hence the LCM technique applied in our work was well adapted to collect limited samples in such restricted regions ${ }^{22}$, LCM indeed also increases sample homogeneity, avoids lamina propria cells collection and-enriched sample with epithelial cells of interest, while limiting the impact of neighbouring tisstes and therefore background signat. ${ }^{38}$ This was further supported by our IHC results, as no SLC12A2 staining was observed in the lamina propria, suggesting that the SLC12A2 upregulation detected by proteomics might have been due to a high purity in epithelial cells content in our FFPE treated samples, limiting strongly contaminations of nonepithelial cells. But more importantly the clinical questions addressed in both previous works were different from the one of our study. They aimed These authors aimed at highlighting proteins able to identify UC-patients at high risk of colorectal dysplasia or cancer and compared proteomes of unpaired colorectal tissues originating from UC patients with and without dysplasiar, whereas our purpose was to identify proteins that were able to discriminate colorectal dysplastic lesions from chronic inflammatory mucosa taken from the same patient. As CAC arises from early dysplastic lesions located in small tissue areas, the LCM applied in our work was well adapted to collect such restricted regions ${ }^{22}$, increasing sample homogeneity by enrichment with epithelial cells. ${ }^{42}$

Our proteomic results were confirmed by $\mathrm{HHC}$ including 28 UC DAI cases with paired inflammatory and normal colorectal tissues, in which most were low grade UC DAI. Early markers to differentiate low-grade UC-DAI from UC-I are the most relevant and considered as a priority for UC patients cancer surveillance, as emphasis by Cremer $A$. et al. in a Belgian national cohort study, where more DAI patients developed high-grade colorectal dysplasia or cancer (9\% and $27 \%$ respectively) during their follow-up compared to DSp patients ( $3 \%$ and $11 \%$ respectively). ${ }^{14,41,42}$

The low number of patients that could be selected for the proteomic study ( $\mathrm{n}=5$ ) and mainly due to technical and design constraints (retrospective FFPE reviewing, 5000 epithelial cells par tissue requirement and paired design) for some patients remains a limitation. However, our paired tissues design overcomes the inter-subject variability allowing higher statistical power achievement than the analysis of unpaired tissues. ${ }^{43,44}$ The patient number is improved in the IHC study ( $\mathrm{n}=28 \mathrm{UC}-\mathrm{DAI}$ cases with paired inflammatory and normal colorectal tissues), focusing on low-grade UC-DAI. Indeed early markers differentiating low-grade UC-DAI from UC-I are the most relevant ones and considered as a priority for UC patients cancer surveillance, as emphasis by Cremer A. et al. based on a Belgian national cohort study, where more DAI patients developed high-grade colorectal dysplasia or cancer (9\% and $27 \%$ respectively) during their follow-up compared to DSp patients (3\% and 11\% respectively). ${ }^{14,45,46}$

In a recent study analysing the transcriptomic changes in patients with longstanding UC to reveal EAC pathways, SLC12^2 was not found differentially expressed between short and longstanding UC A transcriptomic study analysing the samples from patients with UC to reveal CAC pathways could not find SLC12A2 as differentially expressed between short- and long-standing UC. ${ }^{47}$ These data and our results suggest that SLC12A2 upregulation/perturbation does not appear in longstanding UC, but could be specific of inflammation-dysplasia-carcinoma progression as early as low grade dysplasia, as observed in our human (including lesions up to pT4NM CAC stages) and AOM/DSS mice model samples.

In line with our results, Zhang $Y$ et al. who analysed 20 fresh frozen CRC tissues by LCM and label free proteomics identified SLC12A2 as one of the 67 proteins upregulated in CRC (3 times more abundant in CRC than in normal paired tissues). ${ }^{44}$ This is consistent with our observation in non-IBD cancerous lesions and with a previous work of our team using macrodissected tissues and label free 
proteomies, with SLC12 12 being 2 times more abundant in pT1 pT2 CRC compared to normat colorectal tissues. ${ }^{26}$ In the present work, we demonstrated a differential distribution of SLC12A2 IHC staining specific pattern in dysplastic and neoplastic colorectal lesions in the UC context, but also in precancerous and cancerous non IBD colorectal lesions. Altogether, this suggests that SLC12A2 perturbation and upregulation leading to a loss of gradient of expression along the crypts, could be associated to both UC and non-UC colorectal cancer.

In line with our results, Zhang Y et al. found SLC12A2 upregulated in $\mathrm{CRC}^{48}$ which is consistent with a previous work of our team were SLC12A2 was found 2 times more abundant in pT1-pT2 CRC compared to normal colorectal tissues. ${ }^{26}$ Our proteomic and IHC results for SLC12A2 IHC staining pattern in dysplastic and neoplastic colorectal lesions in UC and non-IBD individuals altogether suggest that SLC12A2 perturbation and upregulation leading to a loss of gradient of expression along the crypts, might be associated to both UC and non-UC colorectal cancer progression.

Despite efforts made to identify new histological markers for the diagnosis of colitis associated dysplasia To our knowledge none of the proteins identified to date and proposed as histological diagnosis marker of colitis-associated dysplasia has been recommended in guidelines, consensus, implemented in routine histological evaluation or included in any prospective evaluation trial. ${ }^{15,49-51}$ Ki67, albeit upregulated in colitis-associated dysplasia ${ }^{52}-{ }^{-}$Ki67 has been was shown to be already upregulated in non-dysplastic colon of UC-patients with dysplasia, limiting therefore its use for the distinction of DAI from inflammation. ${ }^{53}$ Moreover, it was shown that the percentage of Ki67 positive cells percentage was reported as already significantly higher in active and inactive UC compared to normal subject mucosa. Consistently we showed a slight but not significant increased percentage of Ki67 positive cells in UC-I and UC-DAI compared to UC-N. Unlike SLC12A2, Ki67 staining was not able to discriminate colorectal dysplasia from chronic colonic inflammation originating from the same patients, suggesting that SLC12A2's pattern is more efficient than the Ki67 for the discrimination of UC-associated dysplasia. The cellular tumour antigen p53 overexpression has been suggested for dysplasia-associated to UC detection ${ }^{54}$, but the ECCO and the ESP jointly emphasised that regenerative epithelium may also show p53 overexpression, limiting therefore its suitability when considered alone as a histological marker. ${ }^{15}$ Detection of $\mathrm{p} 53$ has been suggested in combination with AMACR using a hybrid scoring system based on the semi-quantitative intensity scale and the percentage of positive cells. ${ }^{50}$ Such semi-quantitative assessment can be less reproducible due to inter-observer lower agreement; while the count of positive cells remains rather time consuming for routine analysis if not automated. We obtained preliminary interesting results on the potential added value of p53 in our cases showing false positive or false negative results with SLC12A2 ( $n=6$, data not shown). Another dedicated study should be performed to check for any significant added value of the combined assessment of p53 and SLC12A2.

In our study, SLC12A2 staining pattern appeared more relevant than its staining intensity with a substantial to almost perfect inter-observer agreement. This simple criterion was able to clearly delimit dysplastic from non-dysplastic crypts. Few evidences in the literature might explain the specific this particular loss of gradient pattern in preneoplastic and neoplastic colorectal tissues. SLC12A2 has been described as a stem cell marker in the small intestine ${ }^{55}$. SLC12A2 expression is restricted to the bottom of the crypts, consistent with the staining observed in our normal and inflammatory colorectal tissues., with its expression restricted to the bottom of the crypts consistent with the staining observed in normal and inflammatory colorectal tissues. A hypothesis could be that the expression of SLC12A2 in upper portions of the crypts, including surface epithelia- in dysplastic and cancerous tissues, reflects an onset of cancer stem cells, known to be involved in carcinogenesis and metastasis ${ }^{56,57}$ But in CRC, unlike the stem cell protein Olfactomedin-4 found increased from 
eonventional adenomas to pT2 and of lower abundance in later CRC stages (pT3 and pT4), SLC12 22 increase is maintained in advanced $\mathrm{pT} 3$ and $\mathrm{pT} 4$, suggesting other roles or fate for this protein in eancer progression and likely in the colorectal cancer pathophysiology. But unlike the stem cell protein Olfactomedin-4 found increased from conventional adenomas to pT2 and of lower abundance in later CRC stages (pT3-4), the increase in SLC12A2 is maintained in advanced pT3-4, suggesting other roles or fates for this protein in colorectal cancer pathophysiology. ${ }^{26}$ Ion channels are known to play crucial roles in cell proliferation, differentiation, apoptosis and motility and their dysfunctions could lead to hallmarks of cancer. ${ }^{58}$ SLC12A2 has already been studied in other cancers such as glioma, glioblastoma, lung, pancreatic, hepatocellular, oesophageal and gastric cancers, with suggested roles in epithelial-to mesenchymal transition process, cytoskeleton modulation, EGFR kinase inhibitor resistance and G1/S and G2/M cell cycle progression. ${ }^{59-65}$ However, the role of SLC12 12 in dysplastic or neoplastic colorectal transformation and especially in inflammationassociated neoplastic colorectal transformation remains to be elucidated and is beyond the scope of this paper, as well as the role of other proteins highlighted in our proteomic study, for which genomic or proteomic data exist. However, the role of SLC12A2 (its variants, potential posttranslational modifications, as any other proteins found differentially distributed by proteomics and for which other evidences exist ${ }^{66-69}$ ) in relation to the dysplastic or neoplastic colorectal transformation and especially in inflammation-associated neoplastic colorectal transformation remains to be elucidated and is beyond the scope of this paper.

In conclusion, despite that further studies are warranted to validate SLC12A2 as a clinically useful marker, our results propose SLC12A2 as a promising histological marker for colorectal cancer and dysplasia identification. Here, we showed a specific immunohistochemical SLC12A2 IHC staining pattern in precancerous and cancerous colorectal lesions in the sporadic context and more importantly in ulcerative colitis-UC, where no marker can reliably discriminate inflammation from dysplasia. The SLC12A2 loss of gradient pattern could be an easy IHC parameter that might open new perspectives for CRC and CAC surveillance of UC patients even with persisting disease activity. 


\section{Fundings}

This work was supported by the Télévie [grant number 7.4553.16 to A.-M.M.], the Léon Fredericq foundation and the support of research grant price from the Belgian Week of Gastroenterology 2020, as well as from Dr. Falk (pitch our project research grant sponsoring 2019), ULg internal funding, the Swiss National Science Foundation [grant number 320030_184753 to M.S. and R.M.], the financial support from the Walloon region and the Fonds Européen de Développement Régional for the GIGAfacilities. C.O. is Research Director at the National Funds for Scientific Research (F.R.S.-FNRS, Belgium). 


\section{Conflicts of interest}

The authors declare no conflict of interest. 


\section{Acknowledgments}

We thank S. Azarzar, C. Bachelet, C. Massot, N. Rosière and L. Trzpiot for their precious technical assistance. G. Paulissen, N. Pierre and V. Bertrand for their precious advice and expertise. We thank S. Gofflot, K. El Kandoussi and R. Thonon from the Biothèque Hospitalière Universitaire de Liège (ULiège and CHU de Liège), the CHC Clinique Saint-Joseph of Liège, the CHR Citadelle of Liège, N. Piazzon from the Institute of Pathology of the Centre Hospitalier Universitaire Vaudois, the University Hospital Zurich, and the Immunohistology Facility of the GIGA-institute for the collection and preparation of the sample specimens. The Cardiology laboratory for AOM/DSS mouse model samples. We also thank the GIGA Proteomics Facility and GIGA Flow cytometry and cell imaging facility for their expertise. 


\section{Author contributions}

A.-M.M., F.Q.C., M.-A.M. and E.L. designed the experiment. E.L., M.-A.M., C.M., N.B., S.V., L.d.L., C.S., R.M., M.S., S.B., G.R., C.C.M., A.C., A.V. and P.D. provided the human samples and the clinical information. A.-M.M. performed the sample preparation for the proteomic analysis and the differential analysis. D.B., G.M., and E.D.P. managed the proteomic raw data acquisition and provided advises for the proteomic differential analysis. C.O., L.S. and O.W. performed mice experiments and provided the mice samples. A.-M.M., F.Q.C., C.M. performed human and mice sample preparation for immunohistochemistry analysis. A.-M.M., F.Q.C., C.M., M.-A.M. and N.B. performed the histological characterisation. A.-M.M., M.-A.M. and E.L. analysed the data (including statistics) and wrote the paper. All authors revised the manuscript and improved its intellectual content. 


\section{Supplementary data}

Supplementary data are available at ECCO-JCC online. 


\section{References}

1. Coussens LM., Werb Z. Inflammation and cancer. Nature 2002:860-7. Doi: 10.1038/nature01322.

2. Lang M., Gasche C. Chemoprevention of colorectal cancer. Digestive Diseases 2014:58-67. Doi: $10.1159 / 000366037$.

3. Velayos F., Kathpalia P., Finlayson E. Changing Paradigms in Detection of Dysplasia and Management of Patients With Inflammatory Bowel Disease: Is Colectomy Still Necessary? Gastroenterology 2017;152(2):440-450.e1. Doi: 10.1053/j.gastro.2016.10.006.

4. Lutgens MWMD., van Oijen MGH., van der Heijden GJMG., Vleggaar FP., Siersema PD., Oldenburg B. Declining Risk of Colorectal Cancer in Inflammatory Bowel Disease: an updated meta-analysis of population-based cohort studies. Inflammatory Bowel Diseases 2013;19(4):789-99. Doi: 10.1097/mib.0b013e31828029c0.

5. Singh S., Talwalkar JA. Primary sclerosing cholangitis: Diagnosis, prognosis, and management. Clinical Gastroenterology and Hepatology 2013;11(8):898-907. Doi: 10.1016/j.cgh.2013.02.016.

6. Jess T., Rungoe C., Peyrin-Biroulet L. Risk of Colorectal Cancer in Patients With Ulcerative Colitis: A Meta-analysis of Population-Based Cohort Studies. Clinical Gastroenterology and Hepatology 2012;10(6):639-45. Doi: 10.1016/j.cgh.2012.01.010.

7. Zisman TL., Rubin DT. Colorectal cancer and dysplasia in inflammatory bowel disease. World Journal of Gastroenterology 2008:2662-9. Doi: 10.3748/wjg.14.2662.

8. Beaugerie L., Itzkowitz SH. Cancers complicating inflammatory bowel disease. New England Journal of Medicine 2015:1441-52. Doi: 10.1056/NEJMra1403718.

9. Rogler G. Chronic ulcerative colitis and colorectal cancer. Cancer Letters 2014:235-41. Doi: 10.1016/j.canlet.2013.07.032.

10. Riddell RH., Goldman H., Ransohoff DF., Appelman HD., Fenoglio CM., Haggitt RC., et al. Dysplasia in inflammatory bowel disease: Standardized classification with provisional clinical applications. Human Pathology 1983;14(11):931-68. Doi: 10.1016/S0046-8177(83)80175-0.

11. Mark-Christensen A., Laurberg S., Haboubi N. Dysplasia in Inflammatory Bowel Disease: Historical Review, Critical Histopathological Analysis, and Clinical Implications. Inflammatory Bowel Diseases 2018;24(9):1895-903. Doi: 10.1093/ibd/izy075.

12. Laine L., Kaltenbach T., Barkun A., McQuaid KR., Subramanian V., Soetikno R. SCENIC international consensus statement on surveillance and management of dysplasia in inflammatory bowel disease. Gastroenterology 2015;148(3):639-651.e28. Doi: 10.1053/j.gastro.2015.01.031. 
13. The Paris endoscopic classification of superficial neoplastic lesions: Esophagus, stomach, and colon - November 30 to December 1, 2002. Gastrointestinal Endoscopy, vol. 58. Mosby Inc.; 2003.

14. McKenna BJ., Appelman HD. Dysplasia of the gut: The diagnosis is harder than it seems. Journal of Clinical Gastroenterology 2002:111-6. Doi: 10.1097/00004836-200202000-00002.

15. Magro F., Langner C., Driessen A., Ensari A., Geboes K., Mantzaris GJ., et al. European consensus on the histopathology of inflammatory bowel disease. Journal of Crohn's and Colitis 2013;7(10):827-51. Doi: 10.1016/j.crohns.2013.06.001.

16. O'Sullivan JN., Bronner MP., Brentnall TA., Finley JC., Shen WT., Emerson S., et al. Chromosomal instability in ulcerative colitis is related to telomere shortening. Nature Genetics 2002;32(2):280-4. Doi: 10.1038/ng989.

17. Risques RA., Lai LA., Himmetoglu C., Ebaee A., Li L., Feng Z., et al. Ulcerative colitis-associated colorectal cancer arises in a field of short telomeres, senescence, and inflammation. Cancer Research 2011;71(5):1669-79. Doi: 10.1158/0008-5472.CAN-10-1966.

18. Edge SB., Compton CC. The american joint committee on cancer: The 7th edition of the AJCC cancer staging manual and the future of TNM. Annals of Surgical Oncology 2010:1471-4. Doi: 10.1245/s10434-010-0985-4.

19. Tanaka T., Kohno H., Suzuki R., Yamada Y., Sugie S., Mori H. A novel inflammation-related mouse colon carcinogenesis model induced by azoxymethane and dextran sodium sulfate. Cancer Science 2003;94(11):965-73. Doi: 10.1111/j.1349-7006.2003.tb01386.x.

20. Melgar S., Karlsson A., Michaëlsson E. Acute colitis induced by dextran sulfate sodium progresses to chronicity in C57BL/ 6 but not in BALB/c mice: Correlation between symptoms and inflammation. American Journal of Physiology - Gastrointestinal and Liver Physiology 2005;288(6 51-6). Doi: 10.1152/ajpgi.00467.2004.

21. Bialkowska AB., Ghaleb AM., Nandan MO., Yang VW. Improved swiss-rolling technique for intestinal tissue preparation for immunohistochemical and immunofluorescent analyses. Journal of Visualized Experiments 2016;2016(113). Doi: 10.3791/54161.

22. Longuespée R., Alberts D., Pottier C., Smargiasso N., Mazzucchelli G., Baiwir D., et al. A laser microdissection-based workflow for FFPE tissue microproteomics: Important considerations for small sample processing. Methods 2016;104:154-62. Doi: 10.1016/j.ymeth.2015.12.008.

23. Cox J., Mann M. MaxQuant enables high peptide identification rates, individualized p.p.b.range mass accuracies and proteome-wide protein quantification. Nature Biotechnology 2008;26(12):1367-72. Doi: 10.1038/nbt.1511.

24. Perez-Riverol Y., Csordas A., Bai J., Bernal-Llinares M., Hewapathirana S., Kundu DJ., et al. The PRIDE database and related tools and resources in 2019: improving support for quantification data. Nucleic Acids Research 2019;47. Doi: 10.1093/nar/gky1106. 
25. Tyanova S., Temu T., Sinitcyn P., Carlson A., Hein MY., Geiger T., et al. The Perseus computational platform for comprehensive analysis of (prote)omics data. Nature Methods 2016:731-40. Doi: 10.1038/nmeth.3901.

26. Quesada-Calvo F., Massot C., Bertrand V., Longuespée R., Blétard N., Somja J., et al. OLFM4, KNG1 and Sec24C identified by proteomics and immunohistochemistry as potential markers of early colorectal cancer stages. Clinical Proteomics 2017;14(1). Doi: 10.1186/s12014-0179143-3.

27. Melling N., Kowitz CM., Simon R., Bokemeyer C., Terracciano L., Sauter G., et al. High Ki67 expression is an independent good prognostic marker in colorectal cancer. Journal of Clinical Pathology 2016;69(3):209-14. Doi: 10.1136/jclinpath-2015-202985.

28. Fluge O., Gravdal K., Carlsen E., Vonen B., Kjellevold K., Refsum S., et al. Expression of EZH2 and $\mathrm{Ki}-67$ in colorectal cancer and associations with treatment response and prognosis. British Journal of Cancer 2009;101(8):1282-9. Doi: 10.1038/sj.bjc.6605333.

29. Randolph JJ. Free-Marginal Multirater Kappa (multirater $\mathrm{K}$ free ): An Alternative to Fleiss' Fixed-Marginal Multirater Kappa. Joensuu, Finland; 2005.

30. Odze RD., Goldblum J., Noffsinger A., Alsaigh N., Rybicki LA., Fogt F. Interobserver variability in the diagnosis of ulcerative colitis-associated dysplasia by telepathology. Modern Pathology 2002;15(4):379-86. Doi: 10.1038/modpathol.3880534.

31. Rubin DT., Kavitt RT. Surveillance for Cancer and Dysplasia in Inflammatory Bowel Disease. Gastroenterology Clinics of North America 2006:581-604. Doi: 10.1016/j.gtc.2006.07.001.

32. Evans RL., Park K., James Turner R., Watson GE., Nguyen H van., Dennett MR., et al. Severe impairment of salivation in $\mathrm{Na}+/ \mathrm{K}+/ 2 \mathrm{Cl}$ - cotransporter (NKCC1)-deficient mice. Journal of Biological Chemistry 2000;275(35):26720-6. Doi: 10.1074/jbc.M003753200.

33. Douglas L., Brown PD. Regulatory volume increase in rat lacrimal gland acinar cells. Journal of Membrane Biology 1996;150(2):209-17. Doi: 10.1007/s002329900045.

34. O'Mahony F., Toumi F., Mroz MS., Ferguson G., Keely SJ. Induction of $\mathrm{Na}+/ \mathrm{K}+/ 2 \mathrm{Cl}-$ cotransporter expression mediates chronic potentiation of intestinal epithelial $\mathrm{Cl}$ - secretion by EGF. American Journal of Physiology - Cell Physiology 2008;294(6). Doi: 10.1152/ajpcell.00256.2007.

35. Jakab RL., Collaco AM., Ameen NA. Physiological relevance of cell-specific distribution patterns of CFTR, NKCC1, NBCe1, and NHE3 along the crypt-villus axis in the intestine. American Journal of Physiology - Gastrointestinal and Liver Physiology 2011;300(1). Doi: 10.1152/ajpgi.00245.2010.

36. Randall J., Thorne T., Delpire E. Partial cloning and characterization of Slc12a2: The gene encoding the secretory $\mathrm{Na}+-\mathrm{K}+-2 \mathrm{Cl}$ - cotransporter. American Journal of Physiology - Cell Physiology 1997;273(4 42-4). Doi: 10.1152/ajpcell.1997.273.4.c1267. 
37. Markadieu N., Delpire E. Physiology and pathophysiology of SLC12A1/2 transporters. Pflugers Archiv European Journal of Physiology 2014:91-105. Doi: 10.1007/s00424-013-1370-5.

38. Watanabe M., Fukuda A. Post-translational modification of neuronal chloride transporters. Neuronal Chloride Transporters in Health and Disease. Elsevier; 2020. p. 243-55.

39. Vibat CRT., Holland MJ., Kang JJ., Putney LK., O'Donnell ME. Quantitation of Na+-K+-2Clcotransport splice variants in human tissues using kinetic polymerase chain reaction. Analytical Biochemistry 2001;298(2):218-30. Doi: 10.1006/abio.2001.5398.

40. Brentnall TA., Pan S., Bronner MP., Crispin DA., Mirzaei H., Cooke K., et al. Proteins that underlie neoplastic progression of ulcerative colitis. Proteomics - Clinical Applications 2009;3(11):1326-37. Doi: 10.1002/prca.200900061.

41. May D., Pan S., Crispin DA., Lai K., Bronner MP., Hogan J., et al. Investigating neoplastic progression of ulcerative colitis with label-free comparative proteomics. Journal of Proteome Research 2011;10(1):200-9. Doi: 10.1021/pr100574p.

42. Espina V., Wulfkuhle JD., Calvert VS., VanMeter A., Zhou W., Coukos G., et al. Laser-capture microdissection. Nature Protocols 2006;1(2):586-603. Doi: 10.1038/nprot.2006.85.

43. Rifai N., Gillette MA., Carr SA. Protein biomarker discovery and validation: The long and uncertain path to clinical utility. Nature Biotechnology 2006:971-83. Doi: 10.1038/nbt1235.

44. Stevens JR., Herrick JS., Wolff RK., Slattery ML. Power in pairs: Assessing the statistical value of paired samples in tests for differential expression. BMC Genomics 2018;19(1). Doi: 10.1186/s12864-018-5236-2.

45. de Jong ME., van Tilburg SB., Nissen LHC., Kievit W., Nagtegaal ID., Horjus CS., et al. Longterm Risk of Advanced Neoplasia After Colonic Low-grade Dysplasia in Patients With Inflammatory Bowel Disease: A Nationwide Cohort Study. Journal of Crohn's and Colitis 2019:1485-91. Doi: 10.1093/ecco-jcc/jjz114.

46. Cremer A., Demetter P., de Vos M., Rahier J-F., Baert F., Moreels T., et al. Neoplastic lesions outside diseased area in Inflammatory Bowel Disease patients: A National Cohort Study. Vienna; 2020.

47. Ngah E., Low D., Mokhtar NM., Wong Z., Affendi R., Ali R., et al. Colonic Mucosal Transcriptomic Changes in Patients with Long-Duration Ulcerative Colitis Revealed ColitisAssociated Cancer Pathways. Journal of Crohn's and Colitis 2019:755-63. Doi: 10.1093/eccojcc/jjz002.

48. Zhang Y., Liu Y., Ye Y., Shen D., Zhang H., Huang H., et al. Quantitative proteome analysis of colorectal cancer-related differential proteins. Journal of Cancer Research and Clinical Oncology 2017;143(2):233-41. Doi: 10.1007/s00432-016-2274-5.

49. Dorer R., Odze RD. AMACR immunostaining is useful in detecting dysplastic epithelium in Barrett's esophagus, ulcerative colitis, and Crohn's disease. American Journal of Surgical Pathology 2006;30(7):871-7. Doi: 10.1097/01.pas.0000213268.30468.b4. 
50. Marx A., Wandrey T., Simon P., Wewer A., Grob T., Reichelt U., et al. Combined $\alpha$-methylacyl coenzyme $A$ racemase/p53 analysis to identify dysplasia in inflammatory bowel disease. Human Pathology 2009;40(2):166-73. Doi: 10.1016/j.humpath.2008.06.027.

51. Chen R., Pan S., Lai K., Lai LA., Crispin DA., Bronner MP., et al. Up-regulation of mitochondrial chaperone TRAP1 in ulcerative colitis associated colorectal cancer. World Journal of Gastroenterology 2014;20(45):17037-48. Doi: 10.3748/wjg.v20.i45.17037.

52. Noffsinger AE., Miller MA., Cusi M v., Fenoglio-Preiser CM. The pattern of cell proliferation in neoplastic and nonneoplastic lesions of ulcerative colitis. Cancer 1996;78(11):2307-12.

53. Shinozaki M., Watanabe T., Kubota Y., Sawada T., Nagawa H., Muto T. High proliferative activity is associated with dysplasia in ulcerative colitis. Diseases of the Colon and Rectum 2000;43(10 SUPPL.). Doi: 10.1007/bf02237224.

54. Kobayashi K., Tomita H., Shimizu M., Tanaka T., Suzui N., Miyazaki T., et al. P53 expression as a diagnostic biomarker in ulcerative colitis-associated cancer. International Journal of Molecular Sciences 2017. Doi: 10.3390/ijms18061284.

55. Foulke-Abel J., In J., Yin J., Zachos NC., Kovbasnjuk O., Estes MK., et al. Human Enteroids as a Model of Upper Small Intestinal Ion Transport Physiology and Pathophysiology. Gastroenterology 2016;150(3):638-649.e8. Doi: 10.1053/j.gastro.2015.11.047.

56. Hanahan D., Weinberg RA. Hallmarks of cancer: The next generation. Cell 2011:646-74. Doi: 10.1016/j.cell.2011.02.013.

57. Kim HS., Lee C., Kim WH., Maeng YH., Jang BG. Expression profile of intestinal stem cell markers in colitis-associated carcinogenesis. Scientific Reports 2017;7(1):1-11. Doi: 10.1038/s41598-017-06900-x.

58. Prevarskaya N., Skryma R., Shuba Y. Ion channels in cancer: Are cancer hallmarks oncochannelopathies? Physiological Reviews 2018:559-621. Doi:

10.1152/physrev.00044.2016.

59. Ma H., LiT., Tao Z., Hai L., Tong L., Yi L., et al. NKCC1 promotes EMT-like process in GBM via RhoA and Rac1 signaling pathways. Journal of Cellular Physiology 2019;234(2):1630-42. Doi: 10.1002/jcp.27033.

60. Schiapparelli P., Guerrero-Cazares H., Magaña-Maldonado R., Hamilla SM., Ganaha S., Goulin Lippi Fernandes E., et al. NKCC1 Regulates Migration Ability of Glioblastoma Cells by Modulation of Actin Dynamics and Interacting with Cofilin. EBioMedicine 2017;21:94-103. Doi: 10.1016/j.ebiom.2017.06.020.

61. Sun PL., Jin Y., Park SY., Kim H., Park E., Jheon S., et al. Expression of Na+-K+-2Clcotransporter isoform 1 (NKCC1) predicts poor prognosis in lung adenocarcinoma and EGFRmutated adenocarcinoma patients. QJM 2016;109(4):237-44. Doi: 10.1093/qjmed/hcv207. 
62. Kim J., Jo YH., Jang M., Nguyen NNY., Yun HR., Ko SH., et al. PAC-5 gene expression signature for predicting prognosis of patients with pancreatic adenocarcinoma. Cancers 2019;11(11). Doi: 10.3390/cancers11111749.

63. Zhou Y., Sun W., Chen N., Xu C., Wang X., Dong K., et al. Discovery of NKCC1 as a potential therapeutic target to inhibit hepatocellular carcinoma cell growth and metastasis. Oncotarget 2017;8(39):66328-42. Doi: 10.18632/oncotarget.20240.

64. Shiozaki A., Nako Y., Ichikawa D., Konishi H., Komatsu S., Kubota T., et al. Role of the $\mathrm{Na}+/ \mathrm{K}+/ 2 \mathrm{Cl}$ - cotransporter NKCC1 in cell cycle progression in human esophageal squamous cell carcinoma. World Journal of Gastroenterology 2014;20(22):6844-59. Doi: 10.3748/wjg.v20.i22.6844.

65. Shiozaki A., Miyazaki H., Niisato N., Nakahari T., Iwasaki Y., Itoi H., et al. Furosemide, a blocker of $\mathrm{Na}+/ \mathrm{K}+/ 2 \mathrm{Cl}$ - cotransporter, diminishes proliferation of poorly differentiated human gastric cancer cells by affecting G0/G1 state. Journal of Physiological Sciences 2006;56(6):401-6. Doi: 10.2170/physiolsci.RP010806.

66. Liao F., Dong W., Fan L. Apoptosis of human colorectal carcinoma cells is induced by blocking hepatoma-derived growth factor. Medical Oncology 2010;27(4):1219-26. Doi: 10.1007/s12032-009-9362-1.

67. Pan X., Wang Q., Xu C., Yan L., Pang S., Gan J. Prognostic value of chloride channel accessory mRNA expression in colon cancer. Oncology Letters 2019;18(3):2967-76. Doi: 10.3892/ol.2019.10615.

68. Rappa F., Pitruzzella A., Marino Gammazza A., Barone R., Mocciaro E., Tomasello G., et al. Quantitative patterns of $\mathrm{Hsps}$ in tubular adenoma compared with normal and tumor tissues reveal the value of Hsp10 and $\mathrm{Hsp60}$ in early diagnosis of large bowel cancer. Cell Stress and Chaperones 2016;21(5):927-33. Doi: 10.1007/s12192-016-0721-5.

69. Bjerrum JT., Nielsen OH., Riis LB., Pittet V., Mueller C., Rogler G., et al. Transcriptional Analysis of Left-sided Colitis, Pancolitis, and Ulcerative Colitis-associated Dysplasia. Inflammatory Bowel Diseases 2014;20(12):2340-52. Doi: 10.1097/MIB.0000000000000235. 


\section{Figure legends}

\section{Figure 1. SLC12A2 immunohistochemistry results in AOM/DSS mouse colorectal tissues}

(A) Illustration of the staining pattern frequency distribution among lesion types. (B) Distribution of staining intensity score results in each lesion type. The relevant $p$ values are represented with $* \geq$ $0.01, * * \geq 0.001, * * * \geq 0.0001$ and $* * * *<0.0001$. PBS, normal tissue; I, inflammatory tissue; LGD, low-grade dysplasia; I-LGD, inflammatory tissues associated to LGD; HGD, high-grade dysplasia; IHGD inflammatory tissues associated to HGD; ADC, adenocarcinoma; I-ADC, inflammatory tissues associated to ADC.

\section{Figure 2. SLC12A2 immunohistochemistry in UC-DAI colorectal tissues}

(A) Illustration of the staining pattern frequency distribution among lesion types. (B) Distribution of staining intensity score results in each lesion type. (C) Representative pictures of SLC12A2 IHC staining in UC-N (1), UC-I (2) and UC-DAI (3). Pictures (4), (5) and (6) represent zones in dysplasia, inflammation and at the border of inflammatory and dysplastic areas respectively. The red dotted line in picture (3) separates the dysplastic (right) and the inflammatory (left) tissues. Arrows in picture (4) represent two normal crypts surrounded by dysplastic tissues. Picture (7) represents the negative control. Only significant $p$ values are represented with $* \geq 0.01, * * \geq 0.001, * * * \geq 0.0001$ and $* * * *<$ 0.0001. UC-N, normal tissues from UC-DAI patients; UC-I, inflammatory tissues from UC-DAI patients; UC-DAI, dysplasia associated to UC inflammation.

\section{Figure 3. SLC12A2 immunohistochemistry results in UC-DSp colorectal tissues}

(A) Illustration of the staining pattern frequency distribution among lesion types. (B) Distribution of staining intensity score results in each lesion type. (C) Representative pictures of SLC12A2 IHC staining in UC-N (1) and UC-DSp (2). Only significant $p$ values are represented with $* \geq 0.01, * * \geq$ $0.001, * * * \geq 0.0001$ and $* * * *<0.0001$. UC-N, normal tissues of UC-DSp patients; UC-DSp, dysplasia developed on UC inflammation-free mucosa.

\section{Figure 4. SLC12A2 immunohistochemistry results in UC-CAC colorectal tissues}

(A) Illustration of the staining pattern frequency distribution among lesion types. (B) Distribution of staining intensity score results in each lesion type. (C) Representative pictures of SLC12A2 IHC staining in UC-N (1), UC-I (2) and UC-CAC (3). Only significant $p$ values are represented with * $\geq$ $0.01, * * \geq 0.001, * * * \geq 0.0001$ and $* * * *<0.0001$. UC-N, normal tissue of UC-CAC patient; UC-I, inflammatory tissue of UC-CAC patient; UC-CAC; colitis-associated cancer.

Figure 5. Immunohistochemistry results in longstanding UC showing frequency distribution of SLC12A2 the staining patterns

(A) Normal and inflammatory tissues from dysplasia-free longstanding UC, UC-DAI, UC-DSp and UC-CAC patients are represented. (B) Representative pictures of SLC12A2 IHC staining in UC-N (1) and UC-I (2). UC-N, normal tissue; UC-I, inflammatory tissue. 


\section{Tables}

Table 1. Clinical characteristics of UC patients

\begin{tabular}{|c|c|c|c|c|c|}
\hline Experiment types & $\begin{array}{l}\text { UC-DAI patients } \\
\text { Proteomic }\end{array}$ & Immunohistochemistry & $\begin{array}{l}\text { UC-DSp patients } \\
\text { Immunohistochemistry }\end{array}$ & $\begin{array}{l}\text { UC-CAC patients } \\
\text { Immunohistochemistry }\end{array}$ & $\begin{array}{l}\text { UC non-progressors patients } \\
\text { Immunohistochemistry }\end{array}$ \\
\hline \multicolumn{6}{|l|}{ Sex, $n(\%)$} \\
\hline Female & $1(20)$ & $7(25)$ & $4(44.44)$ & $6(42.86)$ & $7(29.17)$ \\
\hline Male & $4(80)$ & $21(75)$ & $5(55.56)$ & $8(57.14)$ & $17(70.83)$ \\
\hline Age, years median (P25-P75) [NA] & $62(57$ & $64(56.75-69)[8]$ & $67(57-69)[0]$ & $61(44-65)[1]$ & $52.5(48.5-59.5)[0]$ \\
\hline \multicolumn{6}{|l|}{ Smoking habits, $n(\%)$} \\
\hline Smoker & $0(0)$ & $0(0)$ & $0(0)$ & $1(7.14)$ & $1(4.17)$ \\
\hline Non smoker & $5(100)$ & $14(50)$ & $4(44.44)$ & $5(35.71)$ & $20(83.33)$ \\
\hline Not available & $0(0)$ & $14(50)$ & $5(55.56)$ & $8(57.14)$ & $3(12.50)$ \\
\hline UC duration, years median (P25-P27) [NA] & $12(9.25-14.75)[1]$ & $13(6.50-21.50)[9]$ & $10.5(5.75-37.25)[1]$ & $19(12-29.5)[3]$ & $16.5(14-24)[0]$ \\
\hline \multicolumn{6}{|l|}{ UC extent, $n(\%)$} \\
\hline Colon & $4(80)$ & $13(46.43)$ & $3(33.33)$ & & $21(87.50)$ \\
\hline Pancolitis & $1(20)$ & $8(28.57)$ & $0(0)$ & $8(57.14)$ & $9(37.50)$ \\
\hline Descending colon & $2(40)$ & $3(10.71)$ & $1(11.11)$ & $2(14.29)$ & $12(50)$ \\
\hline Sigmoid & $1(20)$ & $2(7.14)$ & $2(22.22)$ & $2(14.29)$ & $0(0)$ \\
\hline Rectum & $0(0)$ & $0(0)$ & $1(11.11)$ & $0(0)$ & $1(4.17)$ \\
\hline Not available & $1(20)$ & $15(53.57)$ & $5(55.56)$ & $2(14.29)$ & $2(8.33)$ \\
\hline \multicolumn{6}{|l|}{ Grade of dysplasia, $n$ (\%) } \\
\hline Low-grade & $5(100)$ & $24(85.71)$ & - & - & - \\
\hline High-grade & $0(0)$ & $4(14.29)$ & - & - & - \\
\hline \multicolumn{6}{|l|}{ Stage of cancer, $n(\%)$} \\
\hline pT1 & - & - & - & $1(7.14)$ & - \\
\hline pT2 & - & - & - & $5(35.71)$ & - \\
\hline pT3 & - & - & - & $7(50)$ & - \\
\hline pT4 & - & - & - & $1(7.14)$ & - \\
\hline \multicolumn{6}{|l|}{ Localisation of dysplasia or cancer, $n$ (\%) } \\
\hline Colon & $5(100)$ & $26(92.86)$ & $1(11.11)$ & $11(78.57)$ & - \\
\hline Caecum & $2(40)$ & $4(14.29)$ & $1(11.11)$ & $0(0)$ & - \\
\hline Ascending colon & $2(40)$ & $3(10.71)$ & $2(22.22)$ & $1(7.14)$ & - \\
\hline Transverse colon & $0(0)$ & $3(10.71)$ & $3(33.33)$ & $3(21.43)$ & - \\
\hline Descending colon & $0(0)$ & $3(10.71)$ & $0(0)$ & $2(14.29)$ & - \\
\hline Sigmoid & $1(20)$ & $4(14.29)$ & $2(22.22)$ & $3(21.43)$ & - \\
\hline Rectum & $0(0)$ & $2(7.14)$ & $0(0)$ & $3(21.43)$ & - \\
\hline
\end{tabular}


Endoscopic morphology of dysplasia, $n(\%)$

Polypoid

Nonpolypoid

$5(100)$

$0(0)$

$11(39.29)$

$2(7.14)$

$3(33.33)$

$2(22.22)$

Not available

$0(0)$

$15(53.57)$

4 (44.44)

Size of the lesions, mm median (P25-P75) [NA]

$4(3.5-4.5)[2] \quad 4(2.75-5)[16]$

$5(3-6)[2]$

$3.5(2.88-4.50)[6]$

Concomitant therapy, $n(\%)$

Aminosalicylates

Corticosteroids

$6(21.43)$

$6(21.43)$

$5(17.86)$

Immunomodulators

$\begin{array}{ll}1(20) & 5(17.86) \\ 1(20) & 4(10.71) \\ 0(0) & 0(0)\end{array}$

None

$\begin{array}{ll}1(20) & 5(17.86) \\ 1(20) & 4(10.7) \\ 0(0) & 0(0)\end{array}$

$6(66.67)$

$3(33.33)$

$0(0)$

$3(33.33)$

$0(0)$

Not available

$8(28.57)$

$0(0)$

$4(28.57)$

$18(75)$

$0(0) \quad 0(0)$

$0(0) \quad 1(4.17)$

$2(14.29) \quad 8(33.33)$

$1(7.14) \quad 2(8.33)$

Other risk factors, $n(\%)$ [NA]

Primary sclerosing cholangitis

$7(50)$

$0(0)$

Family history of colorectal cancer

Legend: NA, not available. 
Table 2. Clinical characteristics of non-IBD patients

A

\section{Conventional adenomas}

Experiment types

Sex, $n(\%)$

Female

Male

Age, years median (P25-P75) [NA

$L G A$

$9(47.37)$

$10(52.63)$

$63(58.50-65.50)[0]$

20

$H G A$

$7(43.75)$

$9(56.25)$

$67(60.5-78)[0]$

$5(31.25)$

$6(37.50)$

$5(31.25)$

$11(68.75)$
$1(6.25)$
$2(12.50)$
$1(6.25)$
$3(18.75)$
$4(25)$
$5(31.25)$

$17(89.47)$

3 (15.79)

$5(26.32)$

$0(0)$

4 (21.05)

5 (26.32)

2 (10.53)

Serrated lesions

$S S A / P$

TSA

$H P P$

$\begin{array}{lll}10(52.63) & 14(73.68) & 9(47.37) \\ 9(47.37) & 5(26.32) & 10(52.63) \\ & & \\ 66(57.5-70.5)[0] & 69(55.5-78.5)[0] & 57(53-67.5)[0]\end{array}$

8 (42.11)

4 (21.05)

$0(0)$

$16(84.21)$

$12(63.16)$

$6(31.58)$

7 (36.84)

3 (15.79)

$1(5.26)$

$18(94.74)$
$4(21.05)$
$5(26.32)$
$3(15.79)$
$2(10.53)$
$4(21.05)$
$1(5.26)$

18 (94.74)

4 (21.05)

5 (26.32)

1 (5.26)

4 (21.05)

4 (21.05)

1 (5.26)

$0(0)$
$4(21.05)$
$2(10.53)$
$0(0)$
$12(63.16)$
$1(5.26)$




\begin{tabular}{|c|c|c|c|c|c|c|c|c|c|}
\hline Experiment types & $\begin{array}{l}\text { pT1 } \\
\text { Cancerous tissue }\end{array}$ & pT1-margin & $\begin{array}{l}\mathbf{p T 2} \\
\text { Cancerous tissue }\end{array}$ & pT2-margin & $\begin{array}{l}\mathbf{p} \mathbf{T} 3 \\
\text { Cancerous tissue }\end{array}$ & pT3-margin & $\begin{array}{l}\text { pT4 } \\
\text { Cancerous tissue }\end{array}$ & pT4-margin & $\begin{array}{l}\text { Normal tiss } \\
\text { Div-Margin }\end{array}$ \\
\hline \multicolumn{10}{|l|}{ Sex, $n(\%)$} \\
\hline Female & $6(31.58)$ & $3(37.50)$ & $12(54.55)$ & $5(50)$ & $9(40.91)$ & $5(50)$ & $9(47.37)$ & $5(50)$ & $9(50)$ \\
\hline Male & $13(68.42)$ & $5(62.50)$ & $10(45.45)$ & $5(50)$ & $13(59.09)$ & $5(50)$ & $10(52.63)$ & $5(50)$ & $9(50)$ \\
\hline Age, years median (P25-P75) $[\mathrm{NA}]$ & $72(62-79.50)[0]$ & $74(70-79.25)[0]$ & $70(64-81)[0]$ & $70(64.75-76.50)[0]$ & $75(73.25-80)[0]$ & $78.5(14.25-80.75)[0]$ & $75(67.50-79)[0]$ & $75.5(68-81.75)[0]$ & $62(47-80.5$ \\
\hline \multicolumn{10}{|l|}{ Smoking habits, $n(\%)$} \\
\hline Smoker & $7(36.84)$ & $5(62.50)$ & $6(27.27)$ & $4(40)$ & $9(40.91)$ & $4(40)$ & $6(31.58)$ & $5(50)$ & $5(27.78)$ \\
\hline Non smoker & $7(36.84)$ & $3(37.50)$ & $11(50)$ & $4(40)$ & $13(59.09)$ & $6(60)$ & $12(63.16)$ & $5(50)$ & $10(55.56)$ \\
\hline Not available & $5(26.32)$ & $0(0)$ & $5(22.73)$ & $2(20)$ & $0(0)$ & & $1(5.26)$ & $0(0)$ & $3(16.67)$ \\
\hline \multicolumn{10}{|l|}{ Localisation of tissue, $n(\%)$} \\
\hline Colon & $13(68.42)$ & $6(75)$ & $19(86.36)$ & $10(100)$ & $21(95.45)$ & $10(100)$ & $17(89.47)$ & $10(10)$ & $18(100)$ \\
\hline Caecum & $2(10.53)$ & $1(12.50)$ & $3(13.64)$ & $2(20)$ & $3(13.64)$ & $3(30)$ & $1(5.26)$ & $1(10)$ & $0(0)$ \\
\hline Ascending colon & $3(15.79)$ & $0(0)$ & $3(13.64)$ & $0(0)$ & $13(59.09)$ & $4(40)$ & $7(36.84)$ & $5(50)$ & $0(0)$ \\
\hline Transverse colon & $0(0)$ & $1(12.50)$ & $0(0)$ & $0(0)$ & $0(0)$ & $1(10)$ & $3(15.79)$ & $1(10)$ & $0(0)$ \\
\hline Descending colon & $2(10.53)$ & $1(12.50)$ & $3(13.64)$ & $1(10)$ & $1(4.55)$ & $1(10)$ & $3(15.79)$ & $2(20)$ & $0(0)$ \\
\hline Sigmoid & $6(31.58)$ & $3(37.50)$ & $10(45.45)$ & $7(70)$ & $4(18.18)$ & $1(10)$ & $3(15.79)$ & $1(10)$ & $18(100)$ \\
\hline Rectum & $6(31.58)$ & $2(25)$ & $3(13.64)$ & $0(0)$ & $1(4.55)$ & $0(0)$ & $2(10.53)$ & $0(0)$ & $0(0)$ \\
\hline
\end{tabular}

Legend: A. Patients with precancerous and non cancerous lesions; B. Patients with CRC; NA, not available. 
Table 3. Results of the differential proteomic analysis

\begin{tabular}{|c|c|c|c|c|}
\hline$\underline{\text { Protein name }}$ & Gene name & Protein ID & Ratio & $p$ value \\
\hline UC-DAI versus UC-I & & & UC-DAI/UC-I & UC-DAI/UC-I \\
\hline Solute carrier family 12 member 2 & $S L C 12 A 2$ & P55011 & UC-DAI only & - \\
\hline Cytochrome c & $C Y C S$ & P99999 & UC-DAI only & - \\
\hline MICOS complex subunit MIC60 & $I M M T$ & Q16891 & UC-DAI only & - \\
\hline Hepatoma-derived growth factor & $H D G F$ & P51858 & UC-DAI only & - \\
\hline Proteasome activator complex subunit 1 & PSME1 & Q06323 & UC-DAI only & - \\
\hline 3-hydroxyisobutyryl-CoA hydrolase, mitochondrial & $\mathrm{HIBCH}$ & Q6NVY1 & UC-DAI only & - \\
\hline Calcium-activated chloride channel regulator 1 & $C L C A I$ & A8K7I4 & 5.36 & 0.0126 \\
\hline $60 \mathrm{kDa}$ heat shock protein, mitochondrial & $H S P D 1$ & P10809 & 1.70 & 0.0056 \\
\hline Protein SET; Protein SETSIP & SET; SETSIP & Q01105; P0DME0 & 1.59 & 0.0078 \\
\hline Tubulin beta- $4 \mathrm{~B}$ chain; Tubulin beta- $4 \mathrm{~A}$ chain & $T U B B 4 B ; T U B B 4 A$ & P68371; P04350 & 1.31 & 0.0069 \\
\hline Clathrin heavy chain 1 & CLTC & Q00610 & 1.25 & 0.0104 \\
\hline UC-DAI versus UC-N & & $>$ & UC-DAI/UC-N & UC-DAI/UC-N \\
\hline Solute carrier family 12 member 2 & $S L C 12 A 2$ & P55011 & UC-DAI only & - \\
\hline Macrophage-capping protein & $C A P G$ & P40121 & UC-DAI only & - \\
\hline Band 4.1-like protein 2 & $E P B 4 I L 2$ & O43491 & UC-DAI only & - \\
\hline $\begin{array}{l}\text { Nascent polypeptide-associated complex subunit alpha; } \\
\text { Nascent polypeptide-associated complex subunit alpha, muscle-specific form }\end{array}$ & $N A C A$ & Q13765; E9PAV3 & 1.98 & 0.0017 \\
\hline Glutathione S-transferase P & GSTPl & P09211 & 1.86 & 0.0019 \\
\hline Protein S100-A6 & $S 100 A 6$ & P06703 & 1.84 & 0.0019 \\
\hline 40S ribosomal protein S27-like & $R P S 27 L$ & Q71UM5 & 1.75 & 0.0001 \\
\hline Heat shock protein HSP 90-beta & $H S P 90 A B 1$ & P08238 & 1.62 & 0.0011 \\
\hline 14-3-3 protein epsilon & $Y W H A E$ & P62258 & 1.52 & 0.0005 \\
\hline $60 \mathrm{kDa}$ heat shock protein, mitochondrial & $H S P D I$ & P10809 & 1.43 & 0.0029 \\
\hline Tubulin beta-4B chain; Tubulin beta- $4 \mathrm{~A}$ chain & $T U B B 4 B ; T U B B 4 A$ & P68371; P04350 & 1.38 & 0.0005 \\
\hline $78 \mathrm{kDa}$ glucose-regulated protein & HSPAS & P11021 & 1.37 & 0.0002 \\
\hline Stress-70 protein, mitochondrial & HSPA9 & P38646 & 1.34 & 0.0024 \\
\hline$\underline{\text { Peroxiredoxin- } 6}$ & PRDX6 & P30041 & 0.46 & 0.0022 \\
\hline UC-I versus $\mathrm{UC}-\mathrm{N}$ & & & UC-I/UC-N & UC-I/UC-N \\
\hline Serum albumin & $A L B$ & P02768 & 2.11 & 0.0413 \\
\hline Protein disulfide-isomerase & $P 4 H B$ & P07237 & 1.71 & 0.0341 \\
\hline Transketolase & $T K T$ & P29401 & 1.58 & 0.0322 \\
\hline L-lactate dehydrogenase A chain & $L D H A$ & P00338 & 1.50 & 0.0463 \\
\hline 40 S ribosomal protein $\mathrm{S} 28$ & $R P S 28$ & P62857 & 1.49 & 0.0339 \\
\hline Protein disulfide-isomerase A3 & PDIA3 & P30101 & 1.48 & 0.0257 \\
\hline Heat shock protein HSP 90-beta & HSP90ABI & P08238 & 1.40 & 0.0017 \\
\hline $78 \mathrm{kDa}$ glucose-regulated protein & $H S P A 5$ & P11021 & 1.40 & 0.0229 \\
\hline $\begin{array}{l}\text { Nascent polypeptide-associated complex subunit alpha; } \\
\text { Nascent polypeptide-associated complex subunit alpha, muscle-specific form }\end{array}$ & $N A C A$ & Q13765; E9PAV3 & 1.35 & 0.0499 \\
\hline Elongation factor 1-delta & EEFID & P29692 & 1.30 & 0.0257 \\
\hline Protein SET; Protein SETSIP & SET; SETSIP & Q01105; P0DME0 & 0.88 & 0.0276 \\
\hline Prelamin-A/C; Lamin-A/C & $L M N A$ & P02545 & 0.87 & 0.0387 \\
\hline ATP synthase subunit alpha, mitochondrial & $A T P 5 A 1$ & P25705 & 0.75 & 0.0198 \\
\hline IgGFc-binding protein & $F C G B P$ & Q9Y6R7 & 0.57 & 0.0269 \\
\hline Peroxiredoxin- 6 & $P R D X 6$ & P30041 & 0.49 & 0.0351 \\
\hline Calcium-activated chloride channel regulator 1 & $C L C A 1$ & A8K7I4 & 0.18 & 0.0254 \\
\hline Selenium-binding protein 1 & SELENBPI & Q13228 & 0.17 & 0.0036 \\
\hline 3-hydroxyisobutyryl-CoA hydrolase, mitochondrial & $\mathrm{HIBCH}$ & Q6NVY1 & UC-N only & - \\
\hline
\end{tabular}

Legend: UC-N, normal tissues from UC-DAI patients; UC-I, inflammatory tissues from UC-DAI patients; UC-DAI, dysplasia associated to UC inflammation; UC-DAI only, protein only quantified in UC-DAI tissues; UC-N only, protein only quantified in UC-N tissues

Table 4. Interobserver agreement statistics for SLC12A2 staining pattern characterisation 


\begin{tabular}{|c|c|c|c|}
\hline Analysis & Overall agreement (\%) & multirater $\kappa_{\text {free }}$ & $95 \%$ confidence interval \\
\hline UC-DAI patients & 93.10 & 0.86 & $0.76-0.97$ \\
\hline UC-N tissues & 85.19 & 0.70 & $0.32-1.00$ \\
\hline UC-I tissues & 93.65 & 0.87 & $0.70-1.00$ \\
\hline UC-DAI tissues & 95.24 & 0.90 & $0.78-1.00$ \\
\hline UC-DSp patients & 100.00 & 1.00 & $1.00-1.00$ \\
\hline UC-N tissues & 100.00 & 1.00 & $1.00-1.00$ \\
\hline UC-DSp tissues & 100.00 & 1.00 & $1.00-1.00$ \\
\hline UC-CAC patients & 93.55 & 0.87 & $0.66-1.00$ \\
\hline UC-N tissues & 100.00 & 1.00 & $1.00-1.00$ \\
\hline UC-I tissues & 91.67 & 0.83 & $0.51-1.00$ \\
\hline UC-CAC tissues & 90.48 & 0.81 & $0.56-1.00$ \\
\hline UC-DAI and UC-DSp and UC-CAC tissues & 94.77 & 0.90 & $0.80-0.99$ \\
\hline Longstanding UC patients & 98.25 & 0.96 & $0.90-1.00$ \\
\hline UC-N tissues & 100.00 & 1.00 & $1.00-1.00$ \\
\hline UC-I tissues & 97.10 & 0.94 & $0.83-1.00$ \\
\hline All UC patients & 95.31 & 0.91 & $0.85-0.96$ \\
\hline Non-IBD precancerous patients & 95.15 & 0.90 & $0.84-0.97$ \\
\hline Div-margin tissues & 100.00 & 1.00 & $1.00-1.00$ \\
\hline LGA tissues & 100.00 & 1.00 & $1.00-1.00$ \\
\hline HGA tissues & 91.11 & 0.82 & $0.58-1.00$ \\
\hline $\mathrm{SSA} / \mathrm{P}$ tissues & 100.00 & 1.00 & $1.00-1.00$ \\
\hline TSA tissues & 92.98 & 0.86 & $0.67-1.00$ \\
\hline HPP tissues & 89.47 & 0.79 & $0.56-1.00$ \\
\hline Non-IBD cancerous patients & 95.09 & 0.90 & $0.85-0.96$ \\
\hline pT1-adjacent and margin tissues & 95.56 & 0.91 & $0.74-1.00$ \\
\hline pT1 tissues & 80.39 & 0.61 & $0.31-0.91$ \\
\hline pT2-adjacent and margin tissues & 100.00 & 1.00 & $1.00-1.00$ \\
\hline pT2 tissues & 90.00 & 0.80 & $0.59-1.00$ \\
\hline pT3-adjacent and margin tissues & 100.00 & 1.00 & $1.00-1.00$ \\
\hline pT3 tissues & 92.98 & 0.86 & $0.67-1.00$ \\
\hline pT4-adjacent and margin tissues & 95.83 & 0.92 & $0.75-1.00$ \\
\hline pT4 tissues & 100.00 & 1.00 & $1.00-1.00$ \\
\hline All non-IBD precancerous and cancerous tissues & 93.51 & 0.87 & $0.81-0.93$ \\
\hline All non-IBD precancerous and cancerous patients & 94.49 & 0.89 & $0.84-0.94$ \\
\hline
\end{tabular}

$\mathrm{N}$, normal; I, inflammatory; DAI, dysplasia associated to UC inflammation; DSp, dysplasia developed on UC inflammation-free mucosa; CAC, colitis-associated cancer; Div-margin, normal tissue taken at surgical margin of diverticulitis; T3T4-margin, normal tissue taken at surgical margin of pT3 or pT4 colorectal cancers; LGA, low-grade conventional adenoma; HGA, high-grade conventional adenoma; SSA/P, sessile serrated adenoma/polyp; TSA, traditional serrated adenoma; HPP, hyperplastic polyp; pT1 to pT4; colorectal cancer from pT1 to pT4 stages; pT1- to pT4-adjacent, normal tissue surrounding pT1 to pT4 colorectal cancers; pT1-pT4-margin, the normal tissue taken at surgical margin of pT1 to pT4 colorectal cancers; All UC-patients, all normal, inflammatory, precancerous and cancerous tissues from UC-DAI, UC-DSp, UC-CAC and longstanding UC patients; All non-IBD precancerous and cancerous tissues, all LGA, HGA, SSA/P, TSA, HPP, pT1, pT2, pT3 and pT4 tissues from non-IBD patients; All non-IBD precancerous and cancerous patients, all LGA, HGA, SSA/P, TSA, HPP, pT1, pT2, pT3, pT4 and normal tissues from non-IBD patients. 
Table 5. Sensitivity, specificity and accuracy of SLC12A2 staining pattern as criteria for tissue classifications

Analysis

UC-DAI versus UC-I

UC-DAI versus (UC-I and UC-N)

UC-DAI versus (UC-I and UC-I from longstanding UC)

UC-CAC versus UC-I

UC-CAC versus (UC-I and UC-N)

UC-CAC versus (UC-I and UC-I from longstanding UC)

(LGA and HGA) versus (Div-margin and T3T4-margin)

(pT1 to pT4) versus (pT-adjacent and pT-margin)

\begin{tabular}{lll} 
Sensitivity & Specificity & Accuracy \\
\hline $89 \%$ & $95 \%$ & $92 \%$ \\
$89 \%$ & $90 \%$ & $90 \%$ \\
$89 \%$ & $86 \%$ & $88 \%$ \\
$93 \%$ & $100 \%$ & $95 \%$ \\
$93 \%$ & $100 \%$ & $97 \%$ \\
$93 \%$ & $83 \%$ & $86 \%$ \\
$83 \%$ & $95 \%$ & $89 \%$ \\
$83 \%$ & $98 \%$ & $90 \%$
\end{tabular}

$\mathrm{N}$, normal; I, inflammatory; UC-DAI, dysplasia associated to UC inflammation; UC-CAC, UCassociated cancer; LGA, low-grade conventional adenoma; HGA, high-grade conventional adenoma; Div-margin, normal tissue taken at surgical margin of diverticulitis; T3T4-margin, normal tissue taken at surgical margin of pT3 or pT4 colorectal cancers; pT1 to pT4; colorectal cancers from pT1 to pT4 stages; pT-adjacent, the normal tissue surrounding pT1 to pT4 colorectal cancers; pT-margin, normal tissue taken at surgical margin of pT1 to pT4 colorectal cancers. 
Figures

Figure 1

A

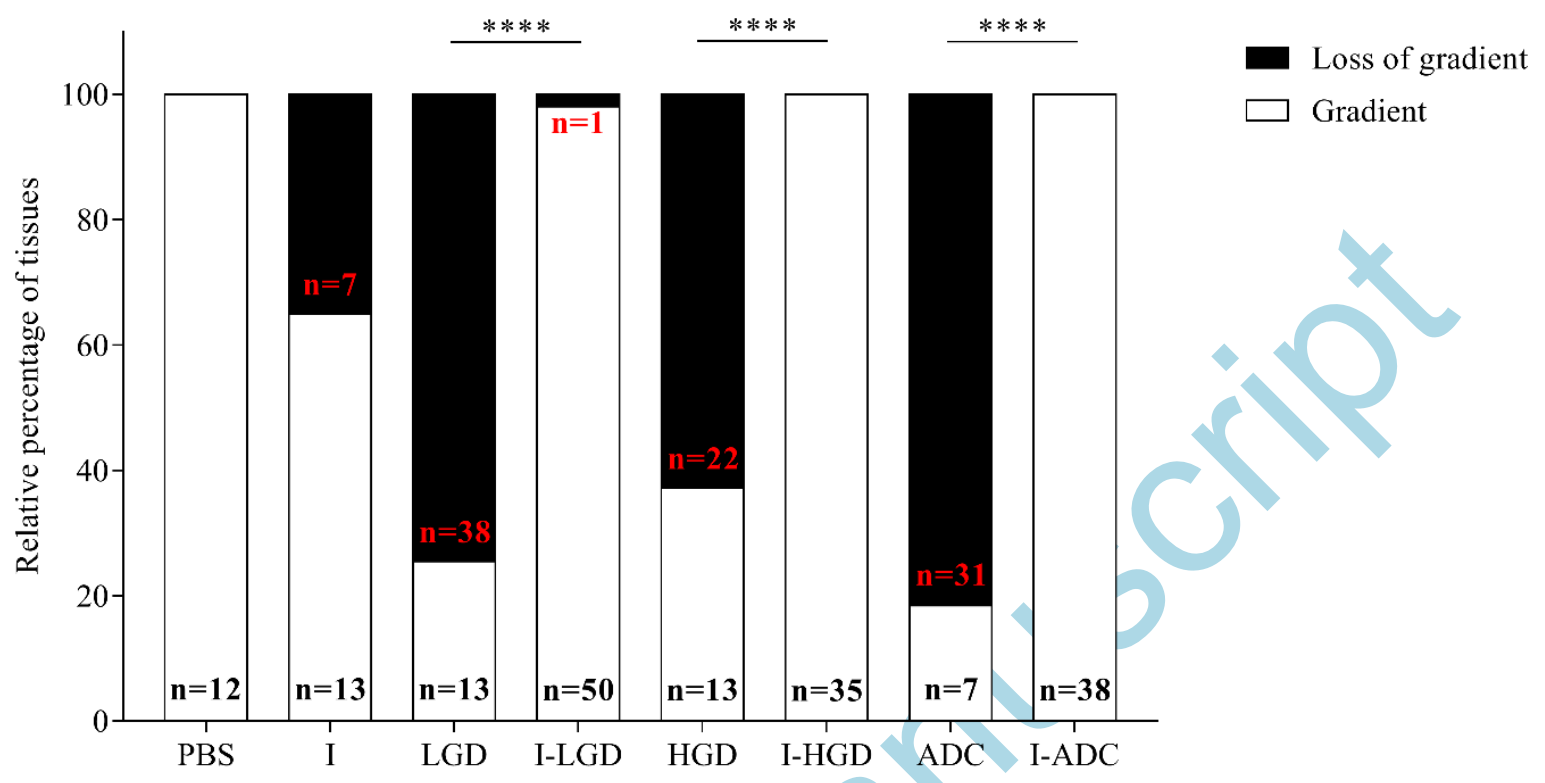

B

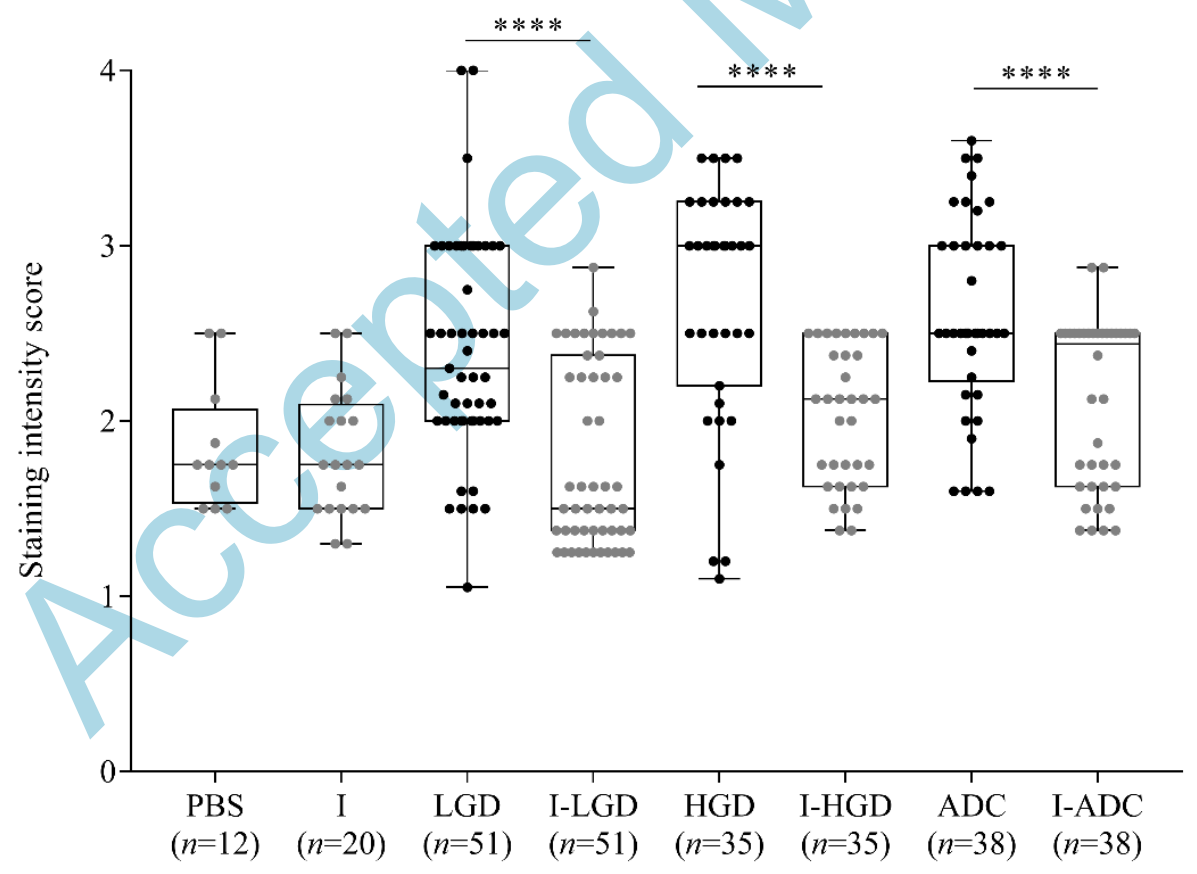


Figure 2

A

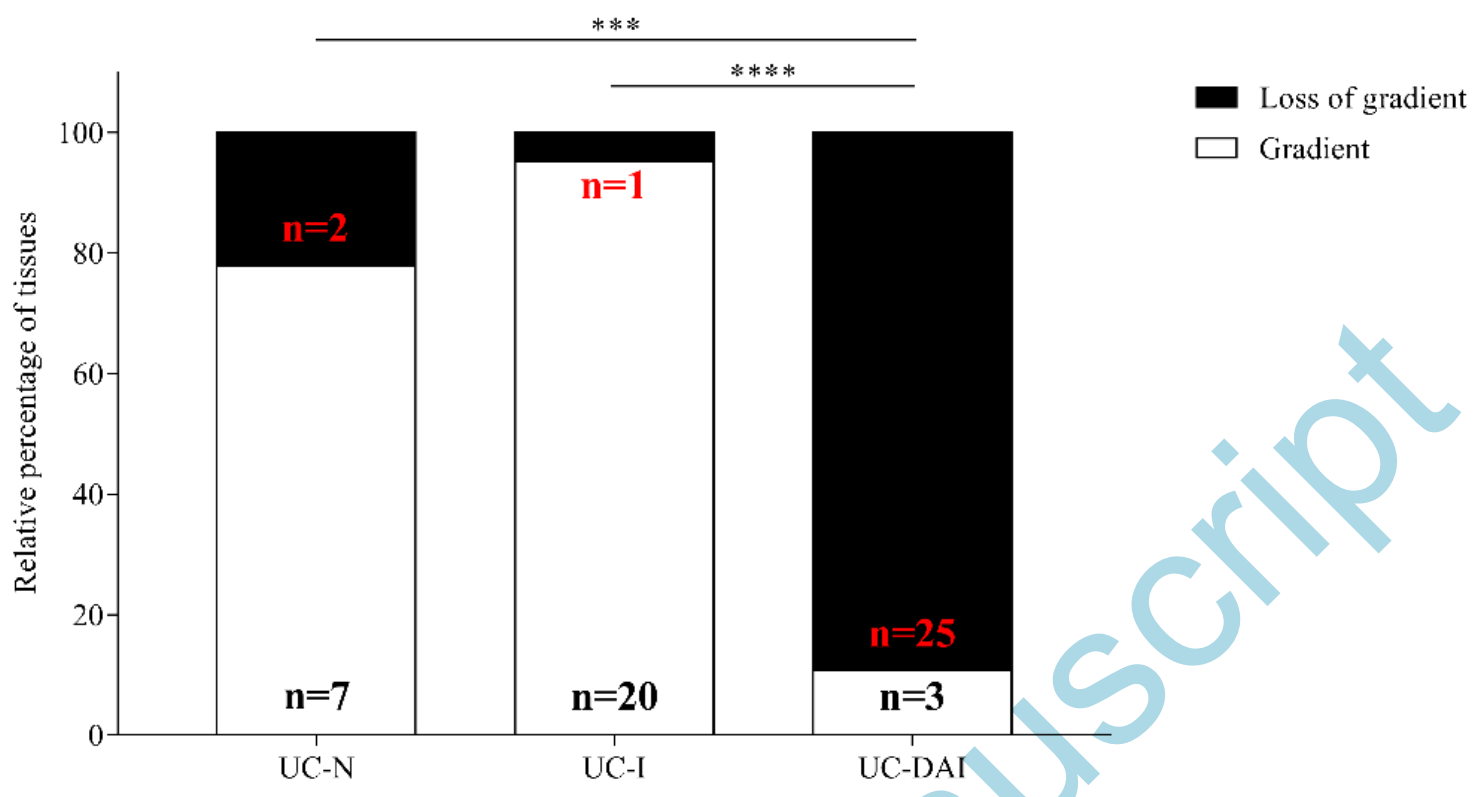

B

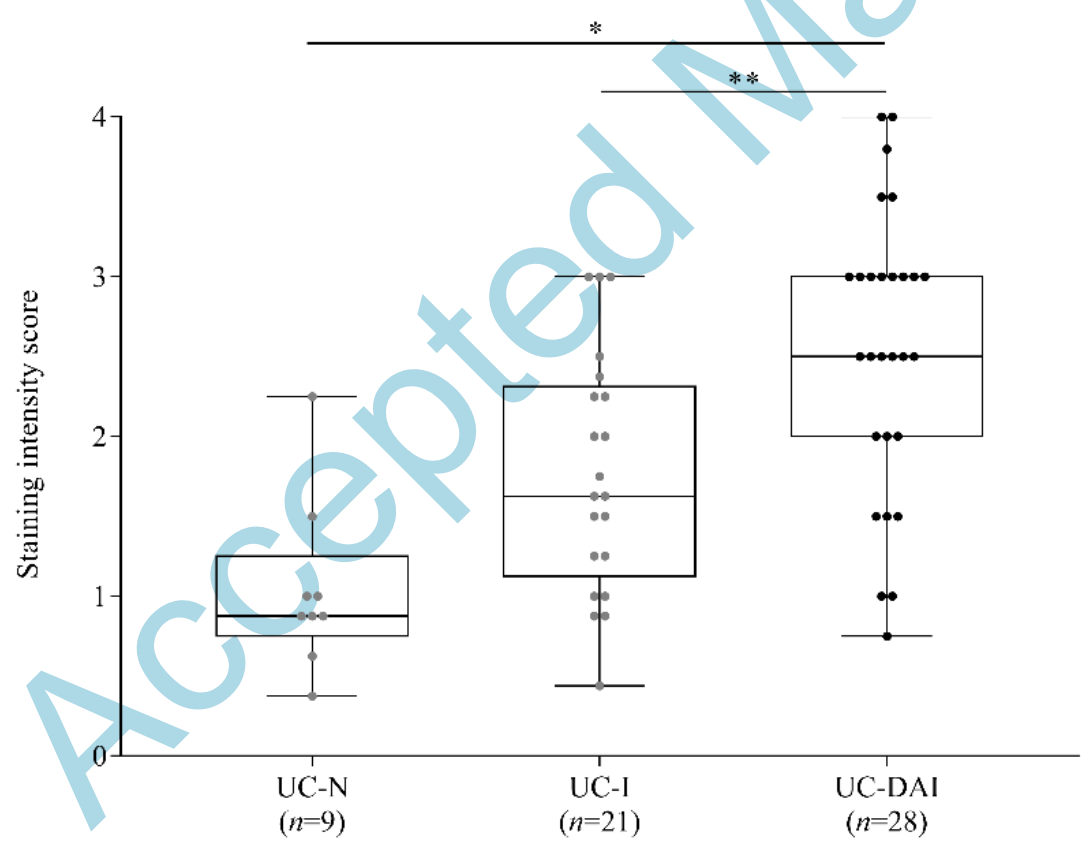


Figure 2C1
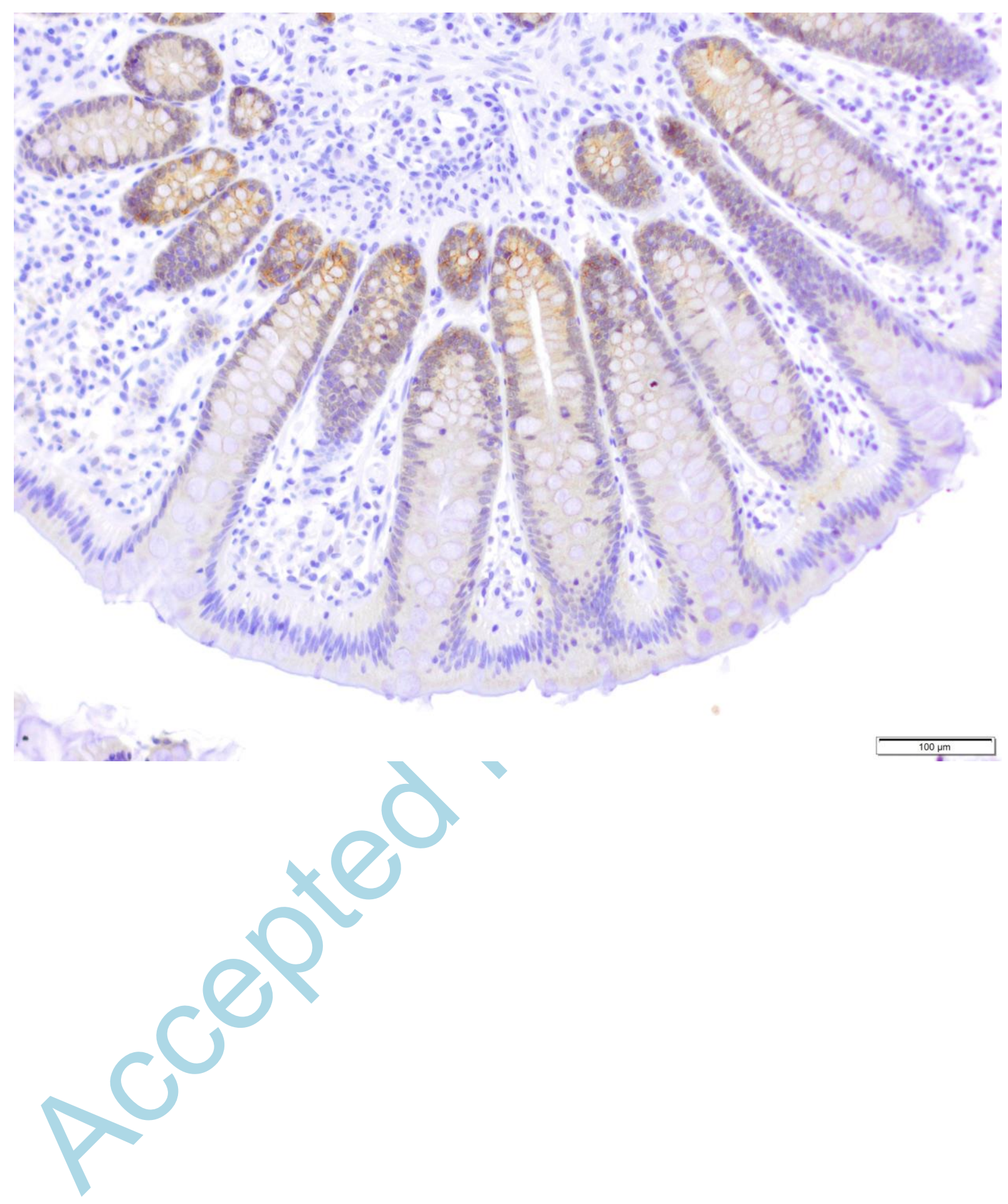
Figure $2 \mathrm{C2}$

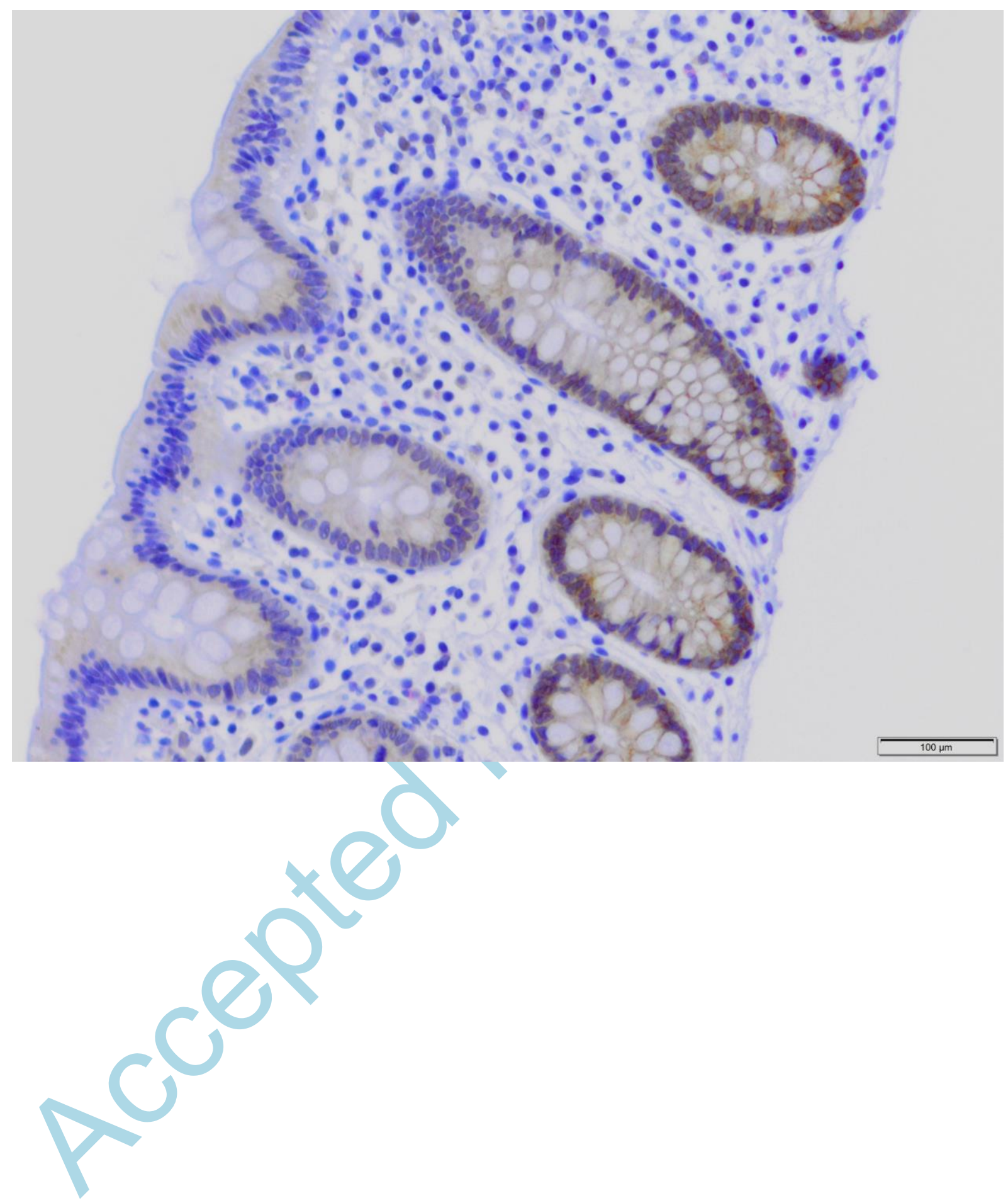


Figure 2C3

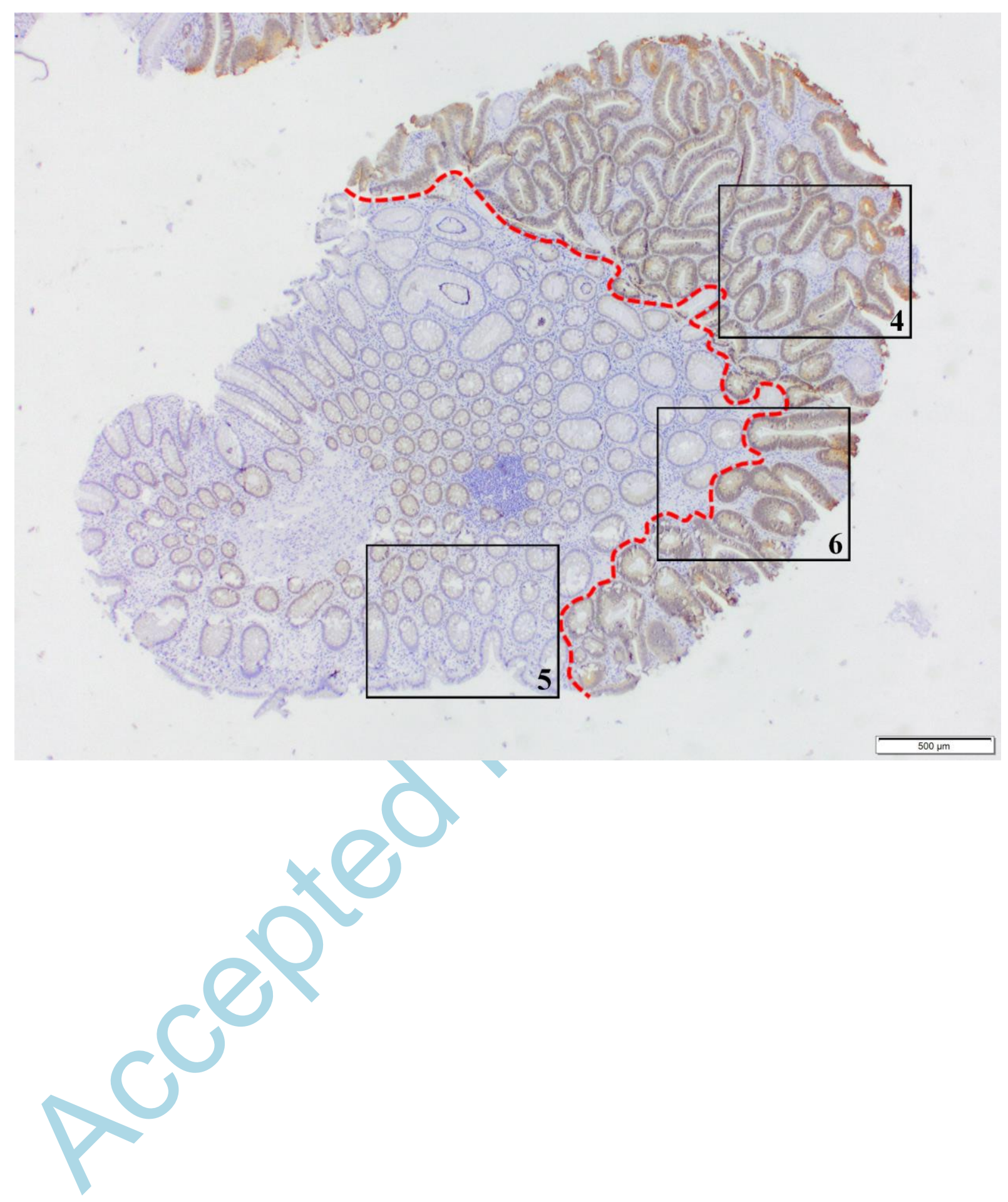


Figure 2C4
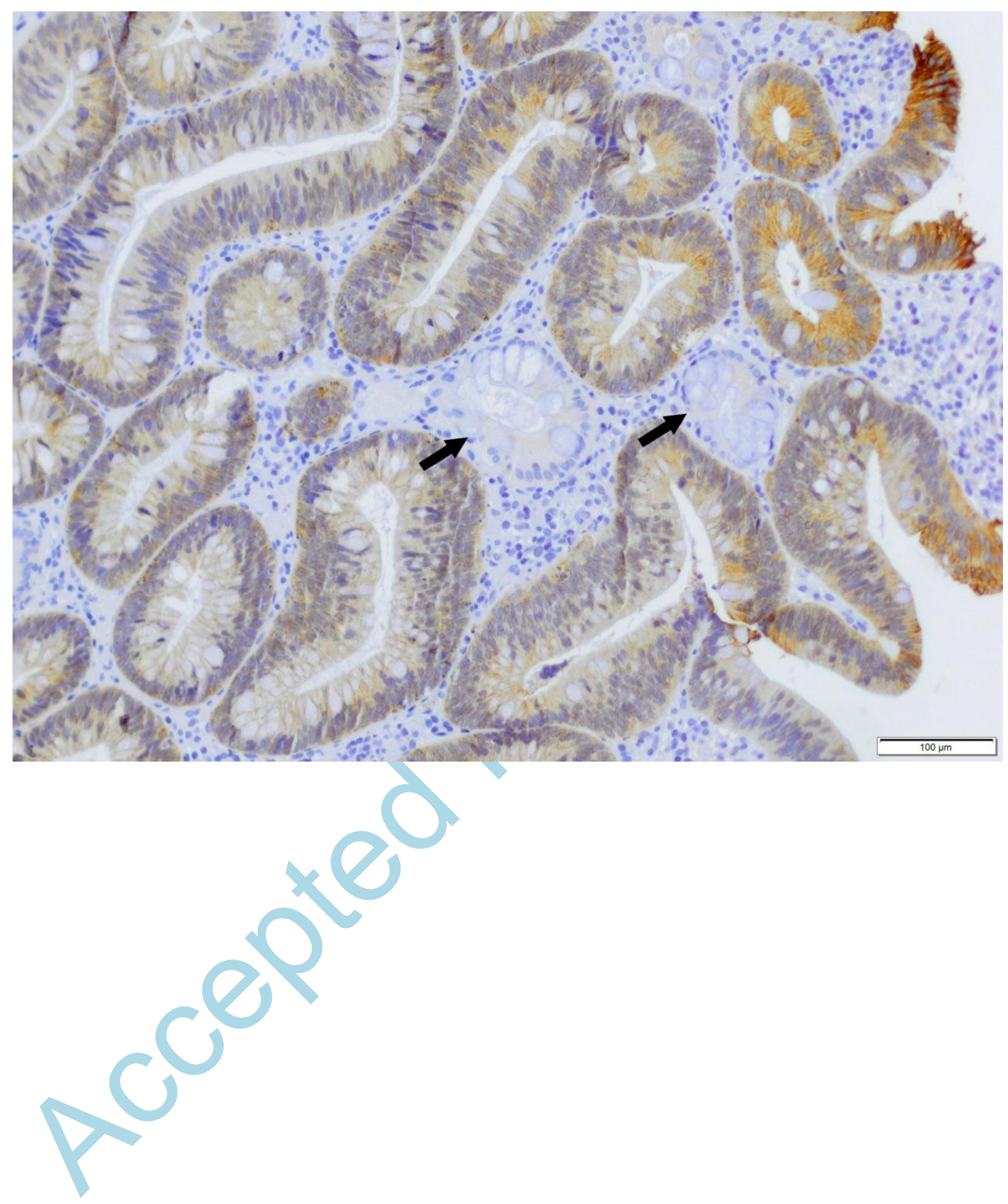
Figure 2C5

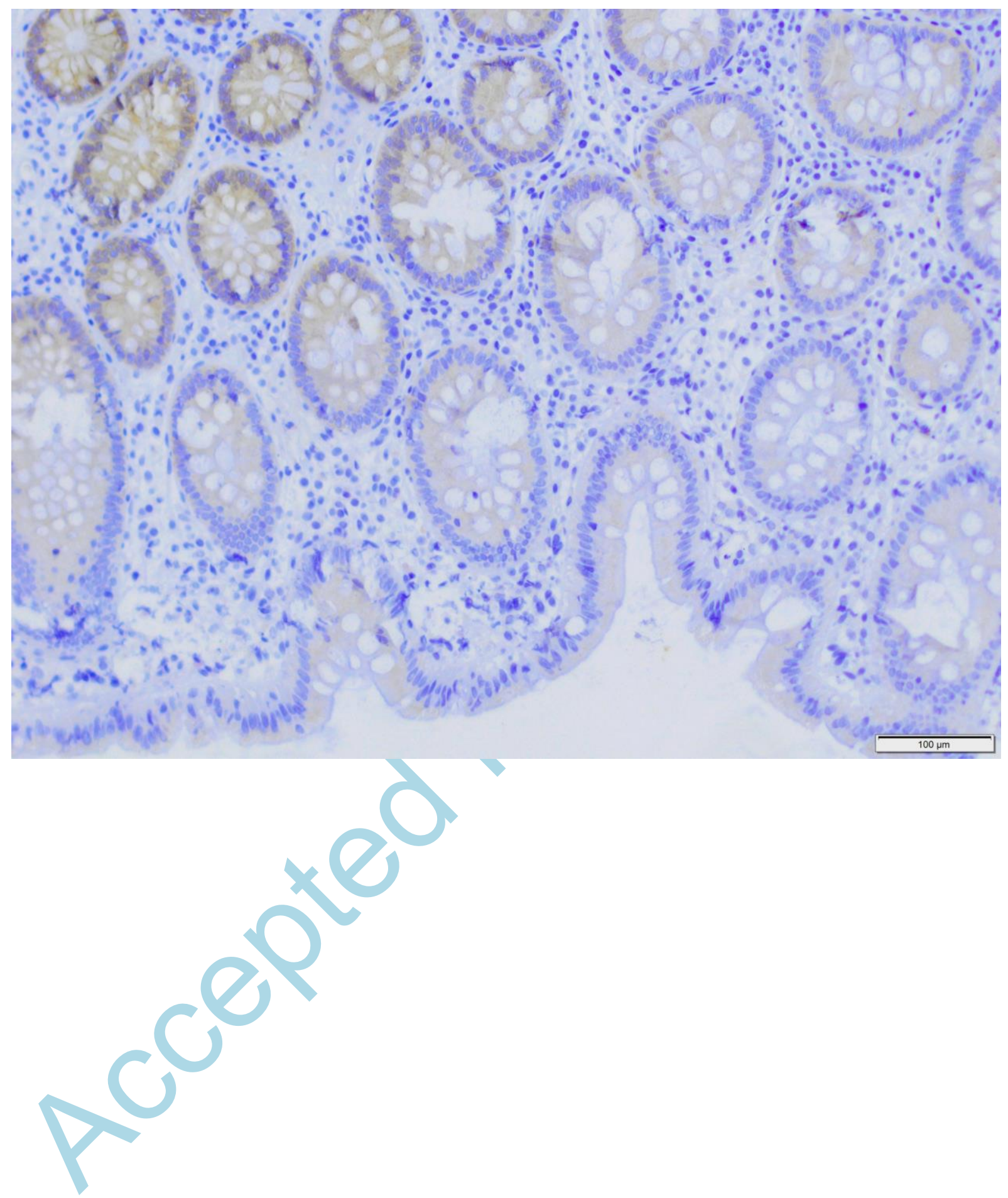


Figure 2C6
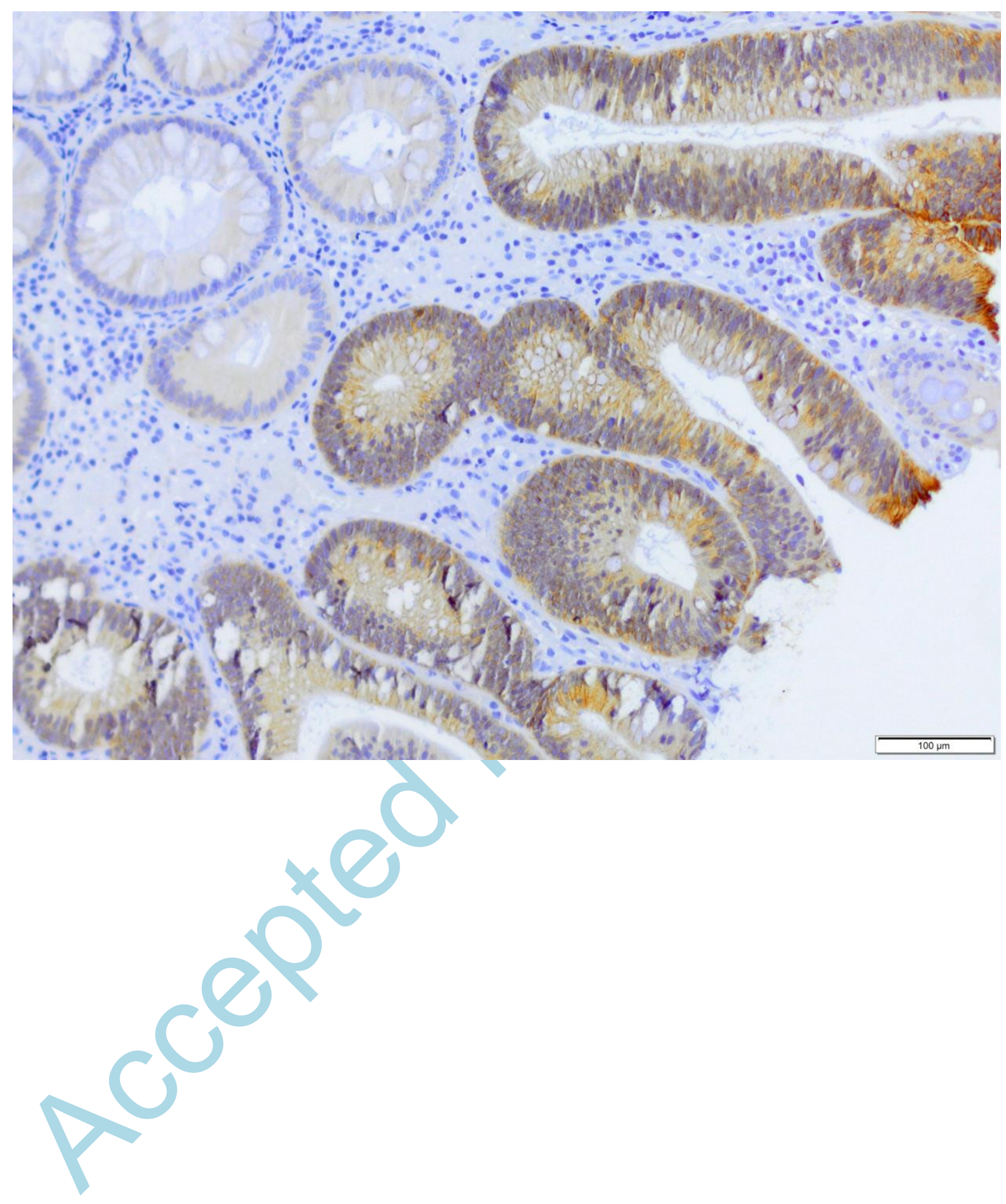
Figure 2C7

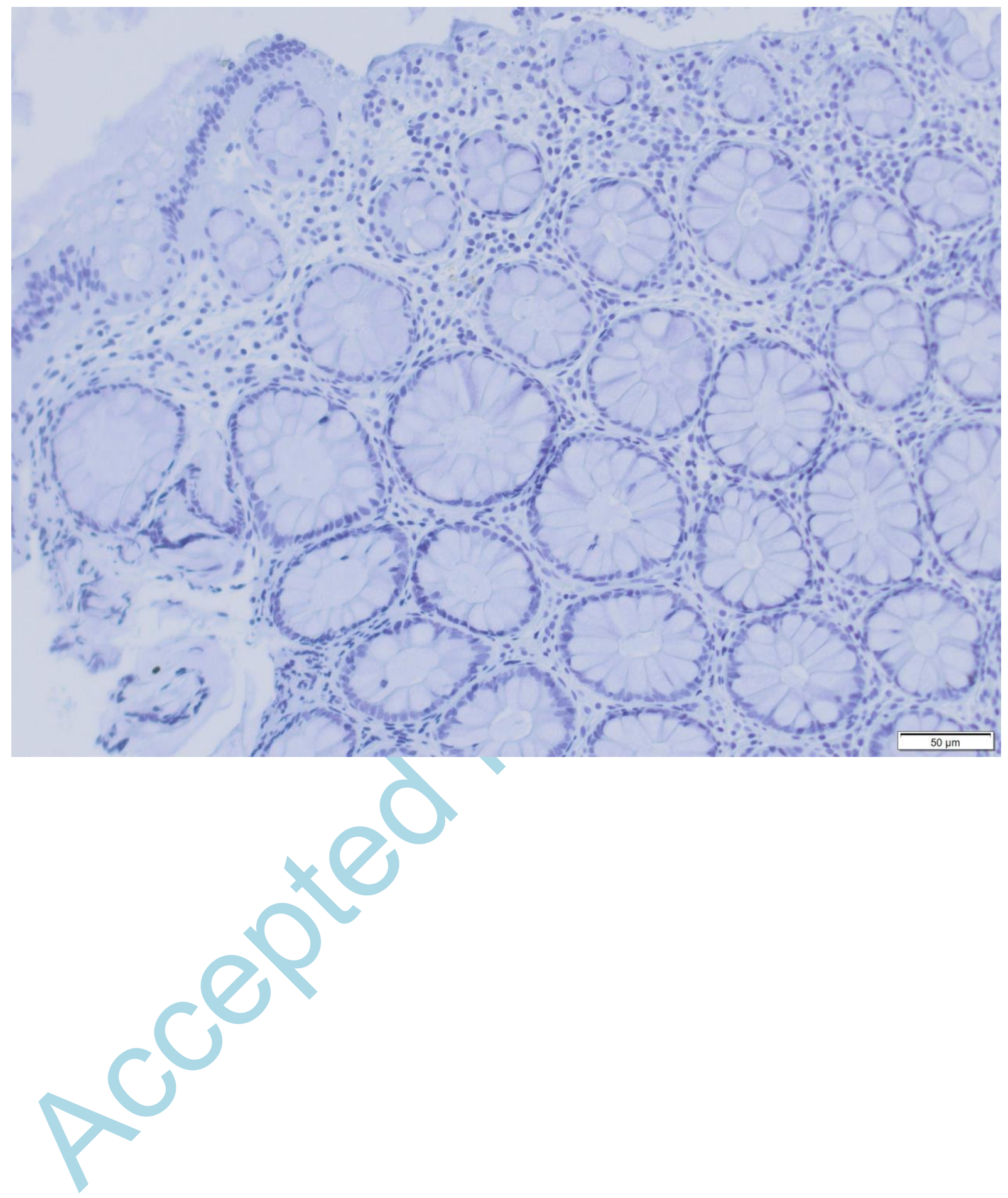


Figure 3

A

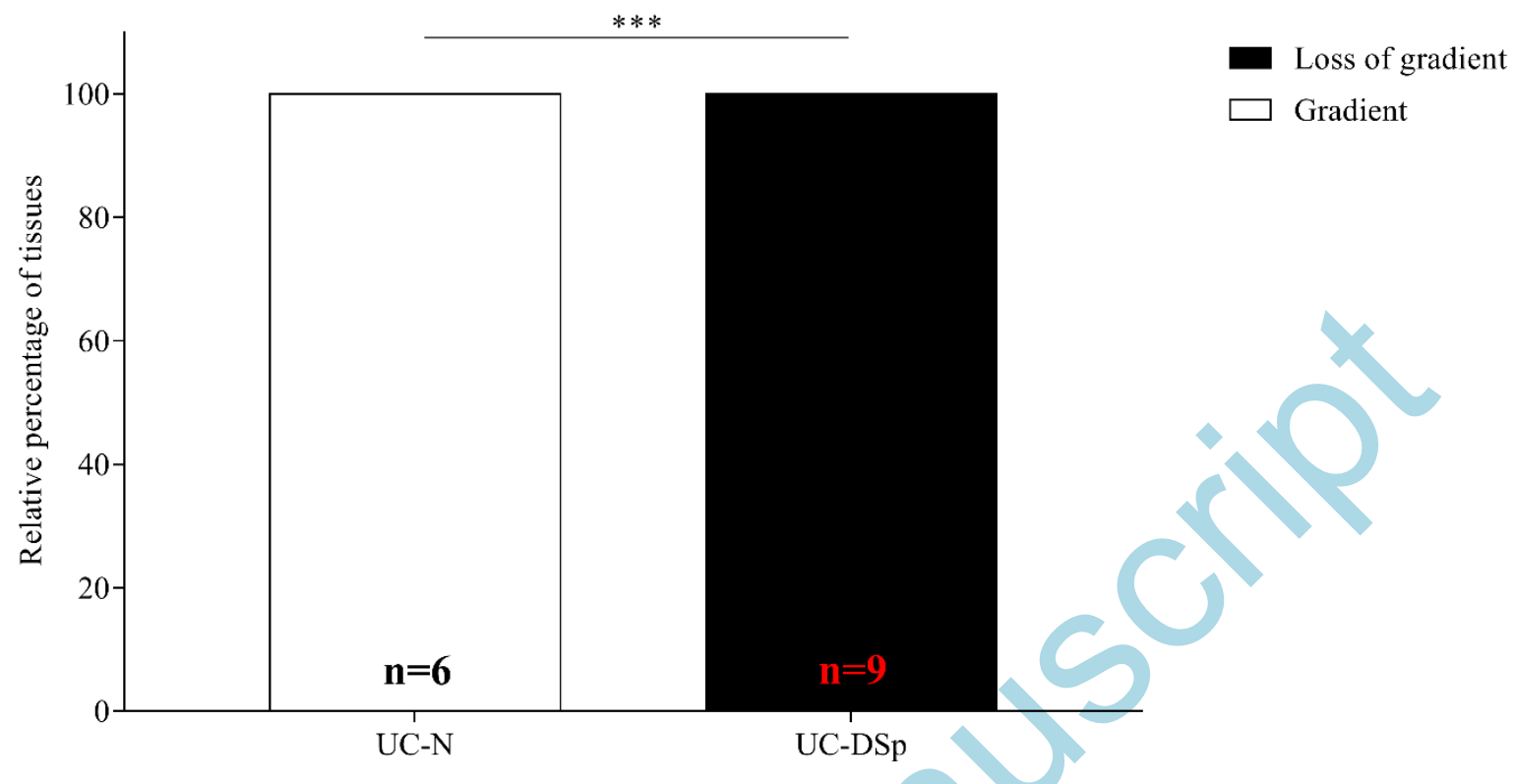

B

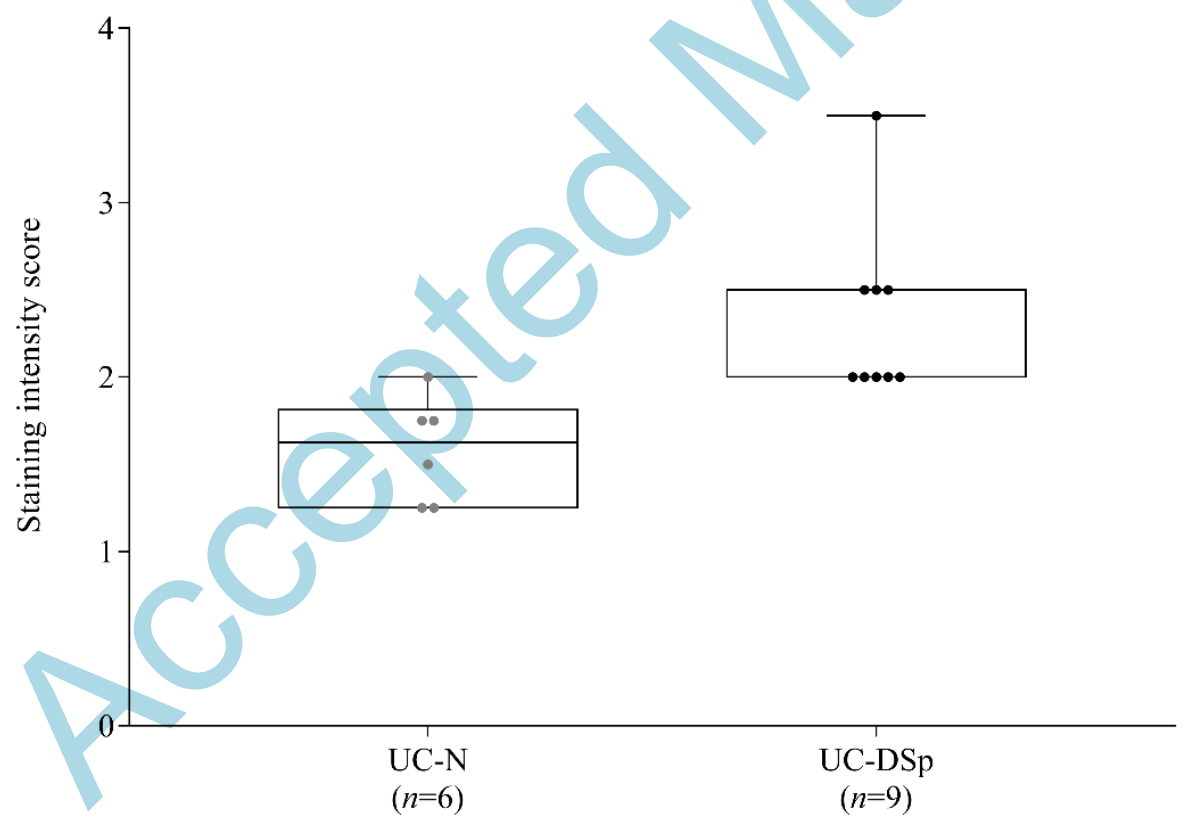


Figure $3 \mathrm{C} 1$
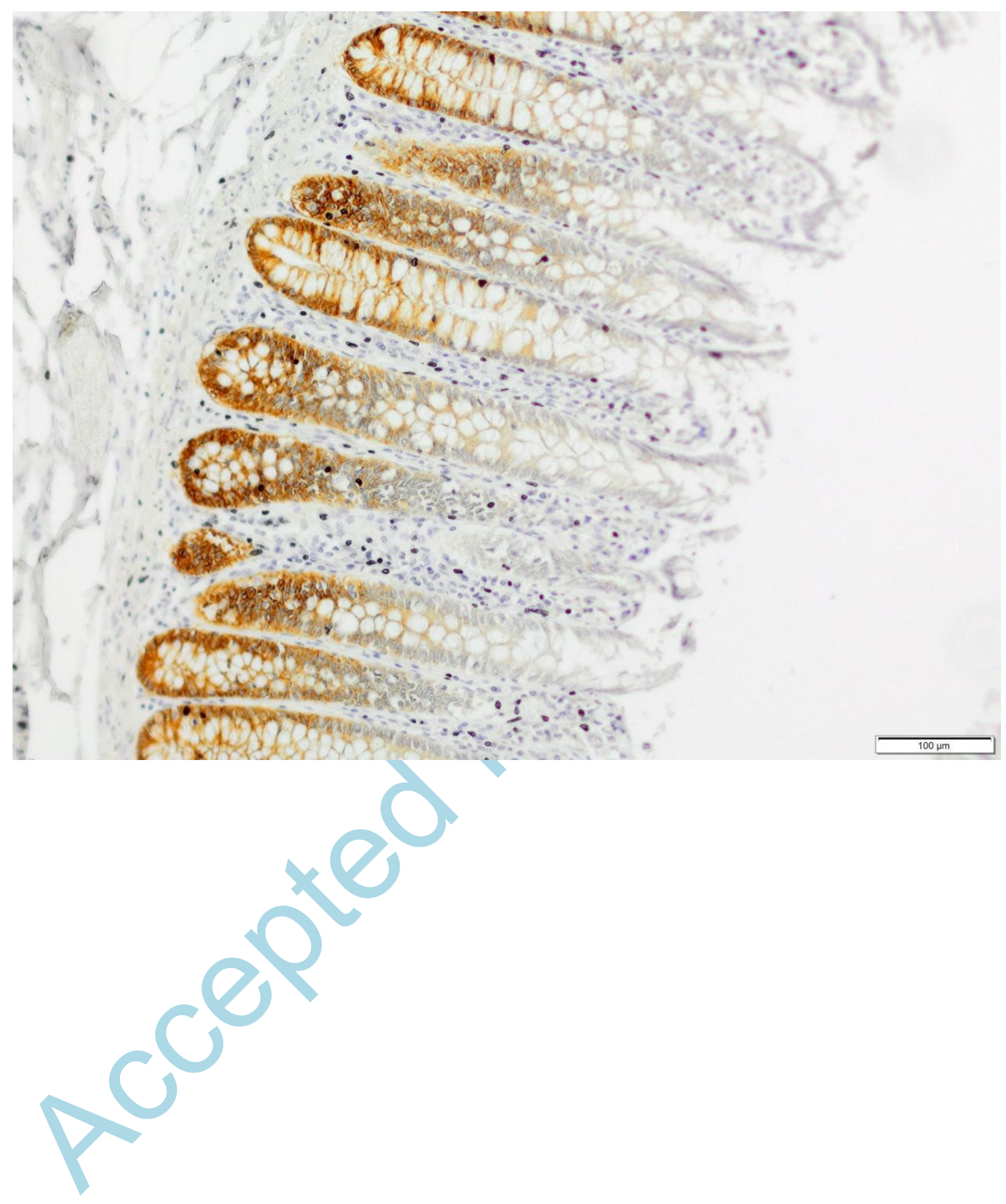
Figure $3 \mathrm{C2}$

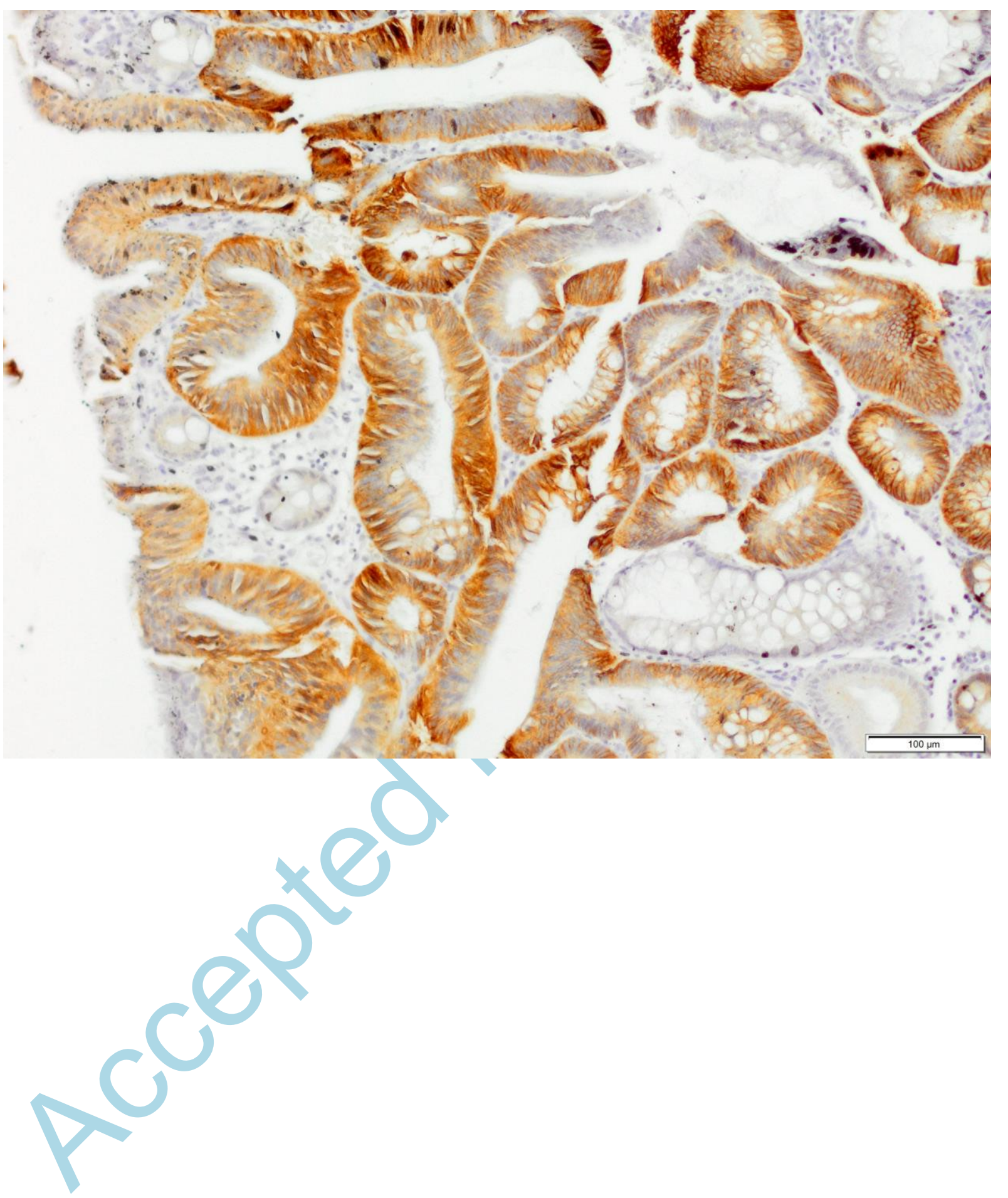


Figure 4

A

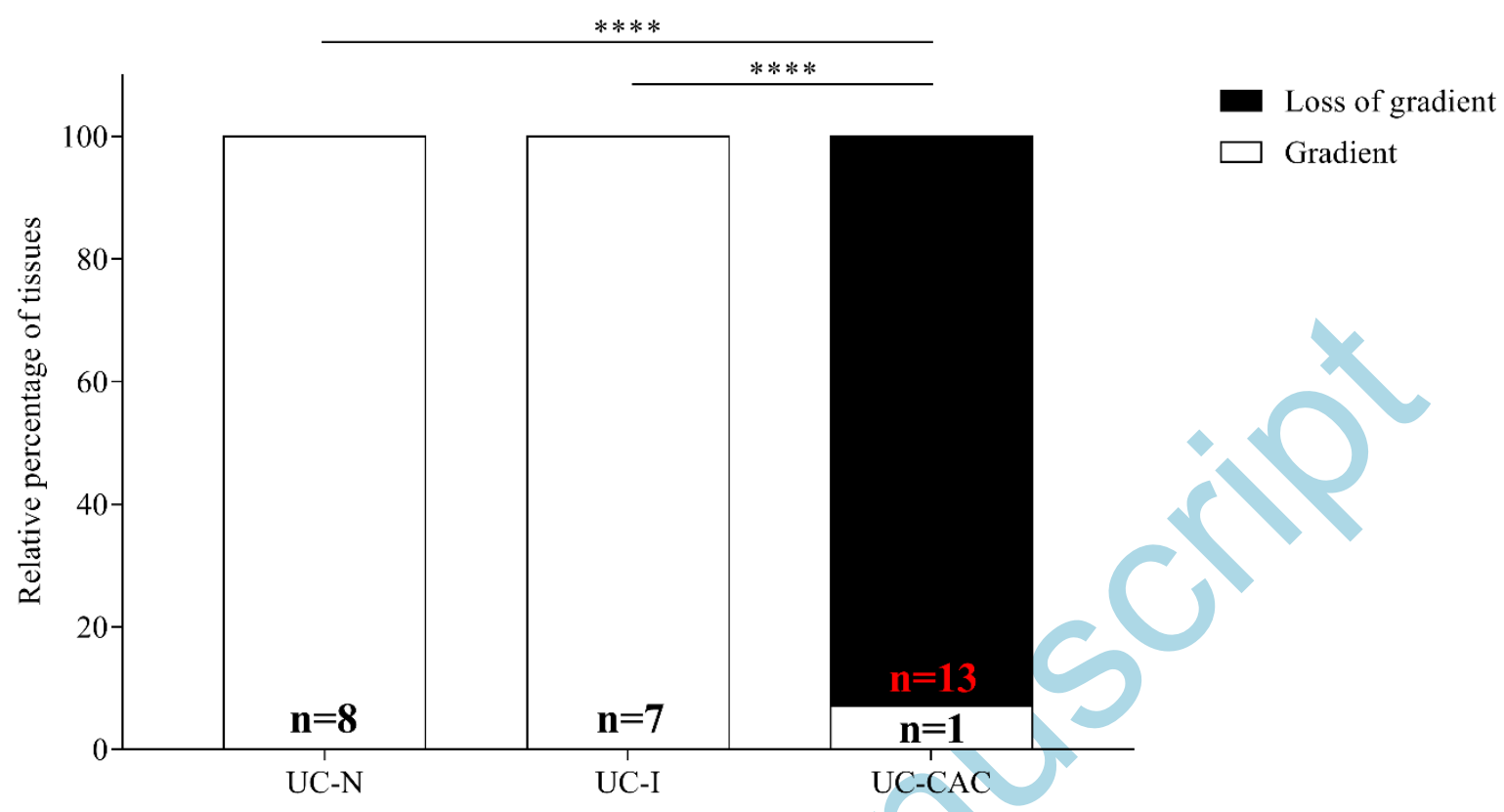

B

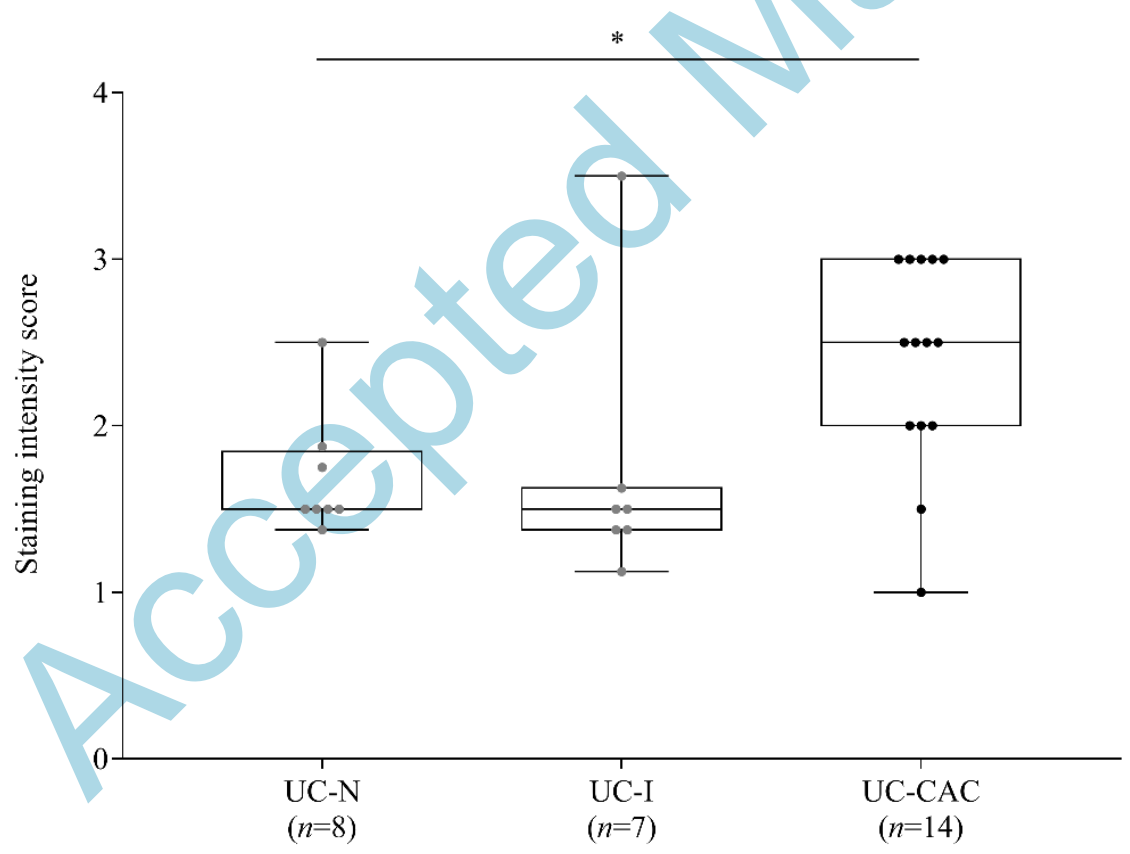


Figure 4C1

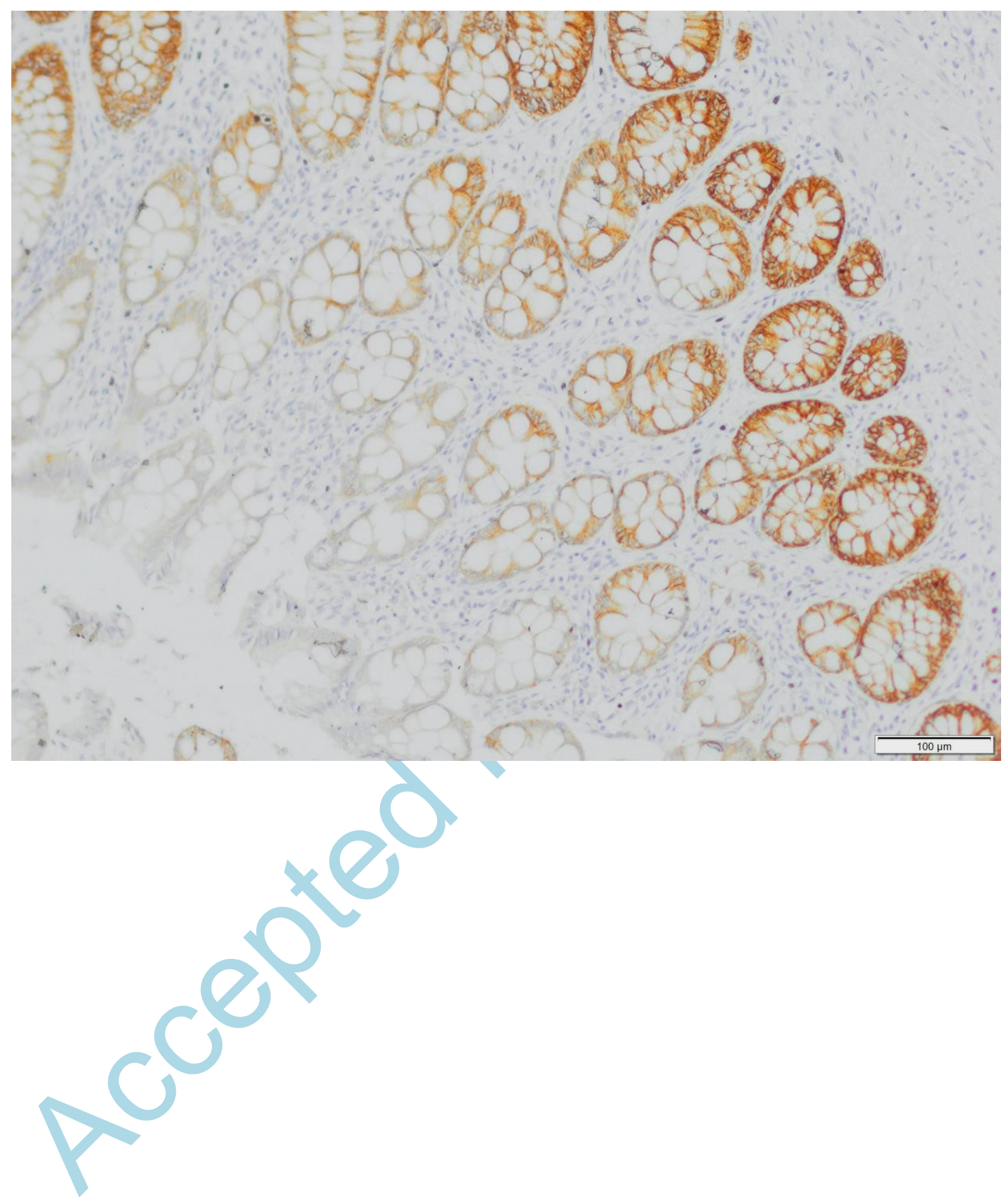


Figure $4 C 2$
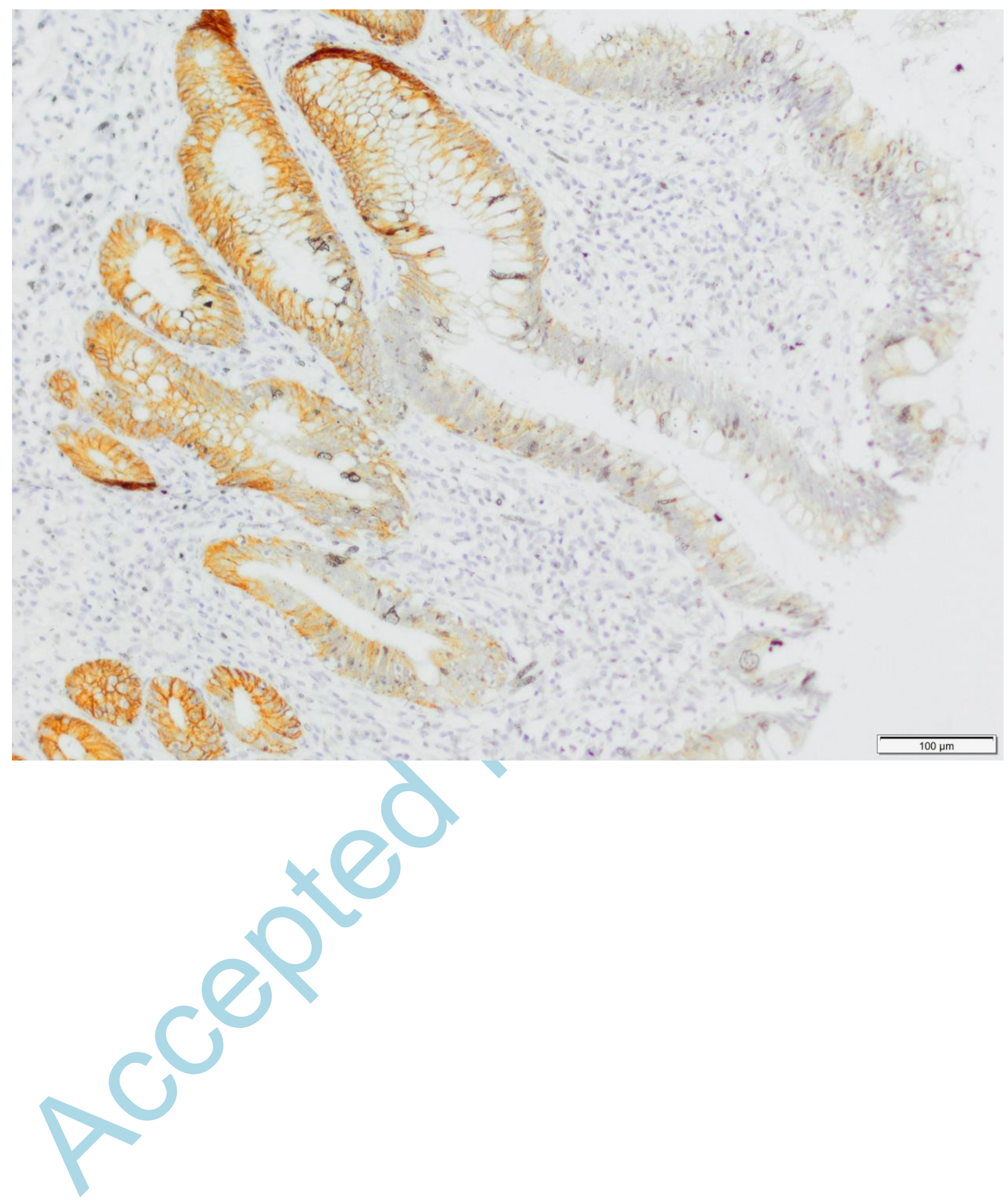
Figure 4C3

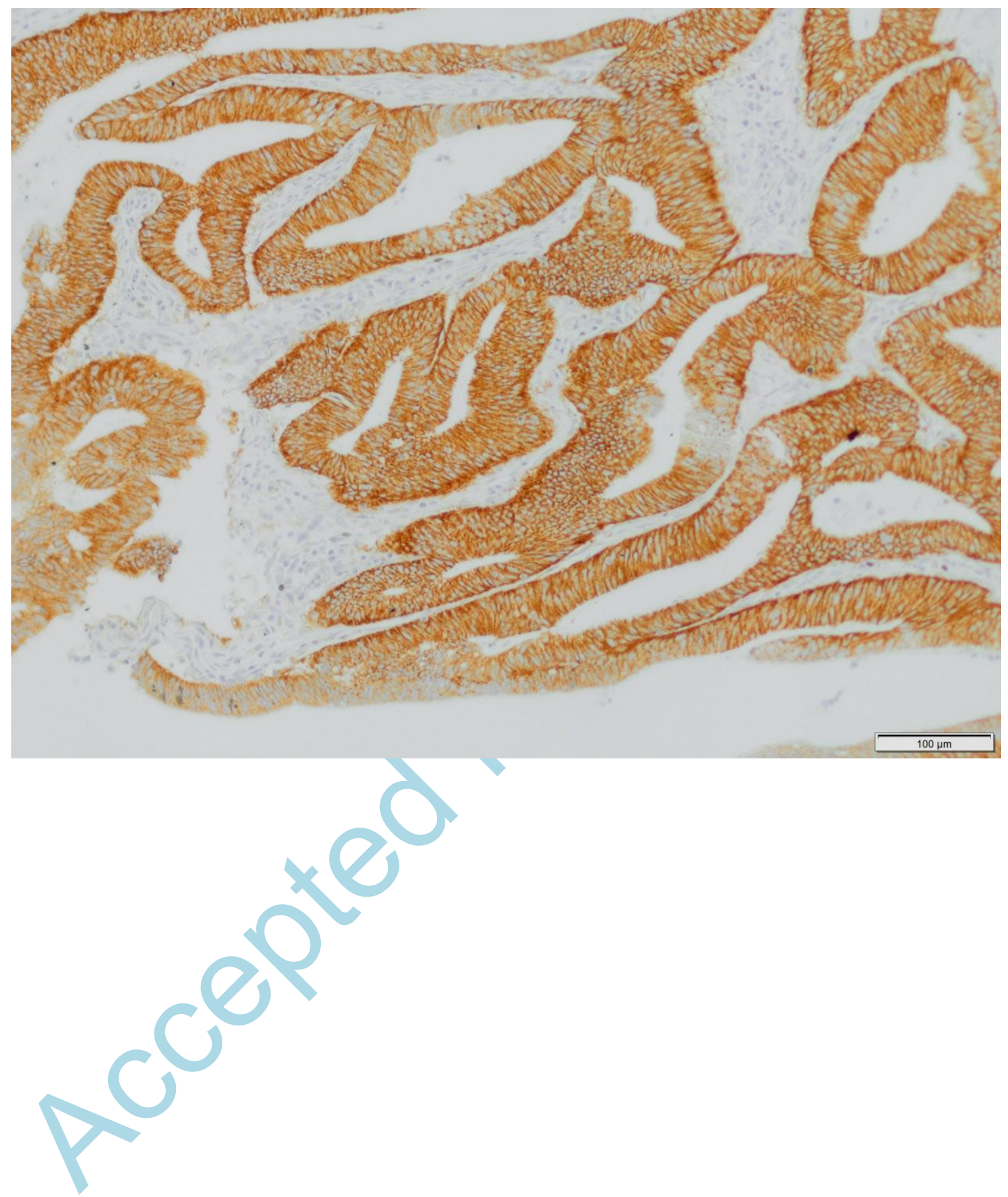


Figure 5

A

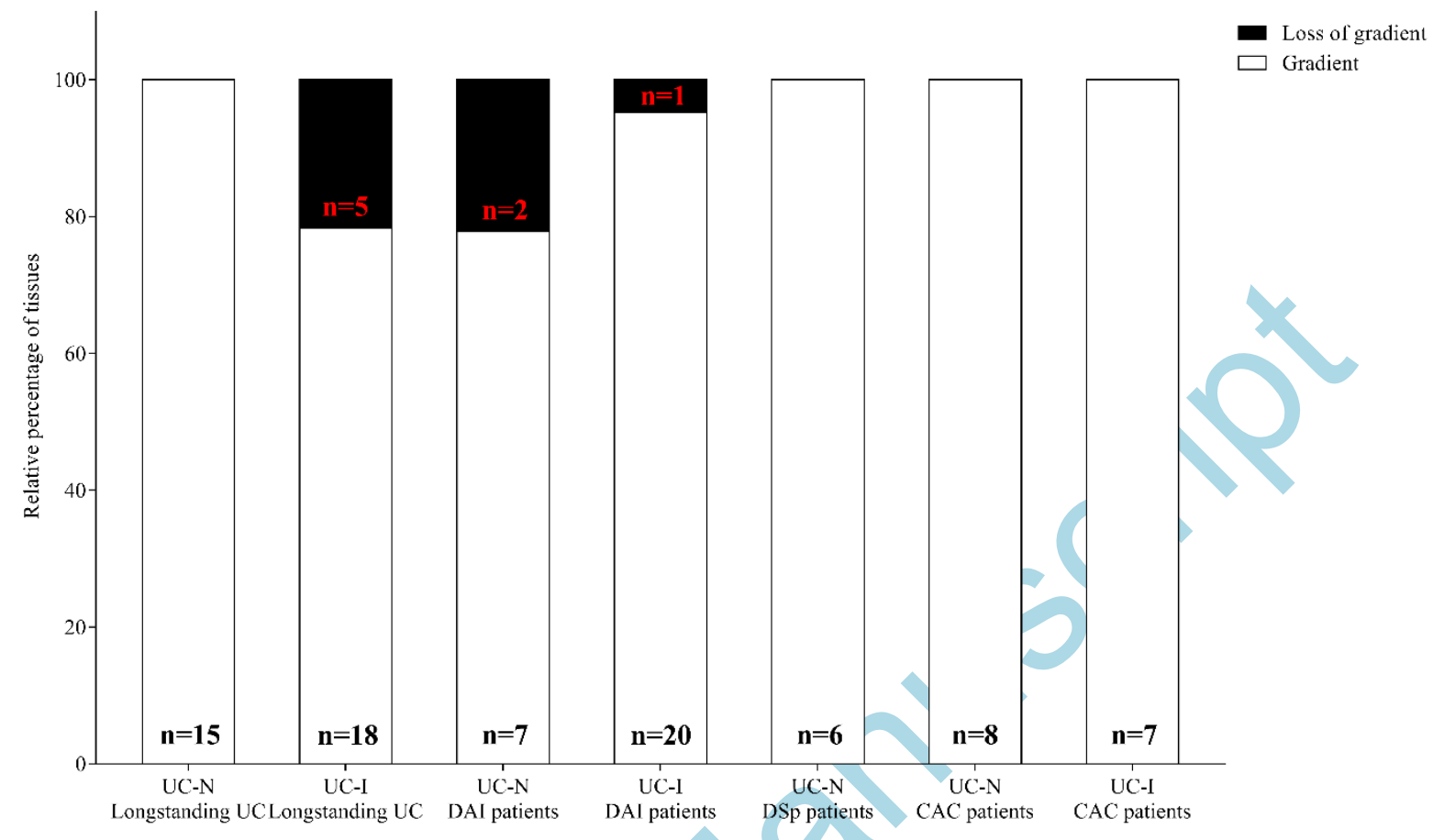


Figure 5B1

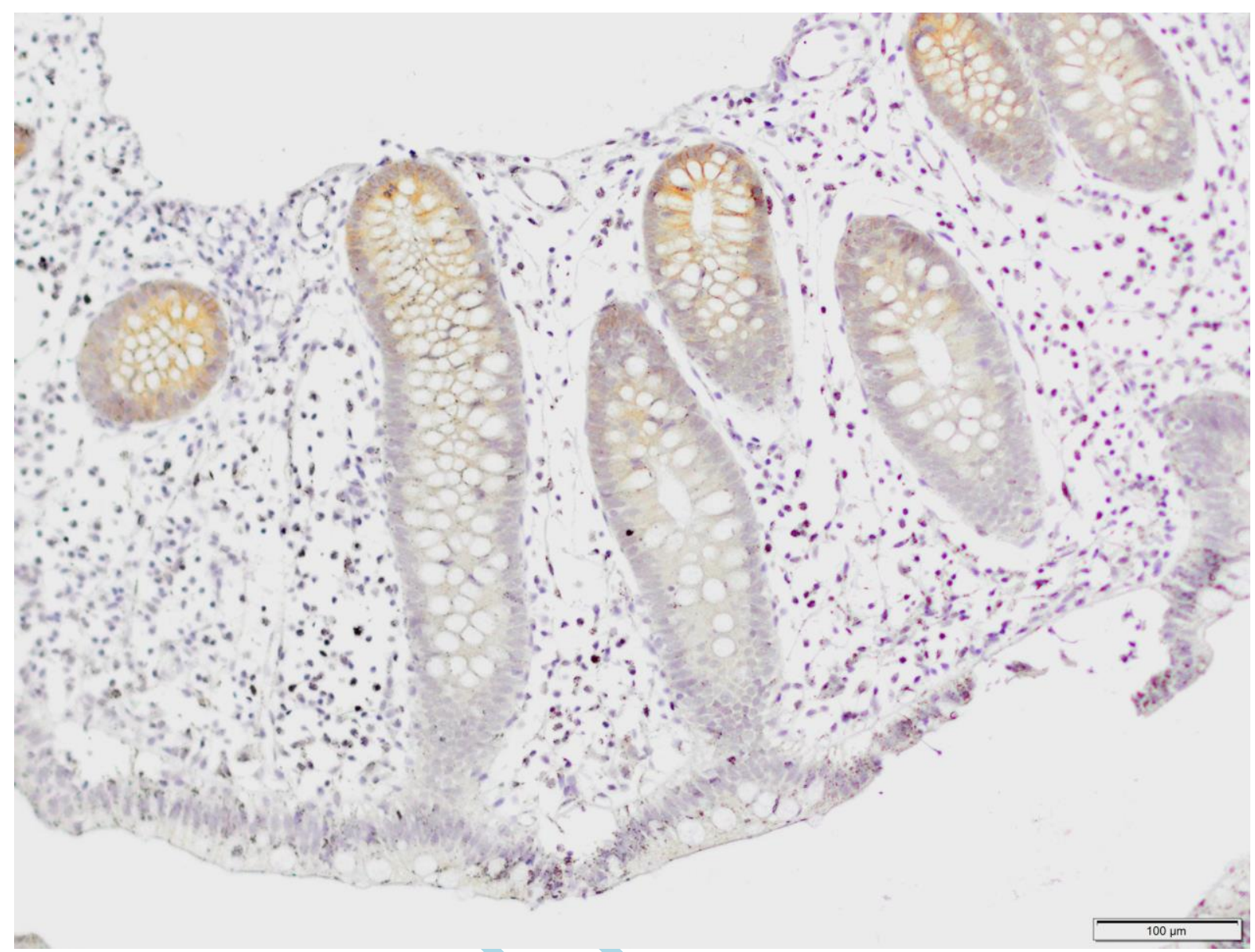


Figure 5B2
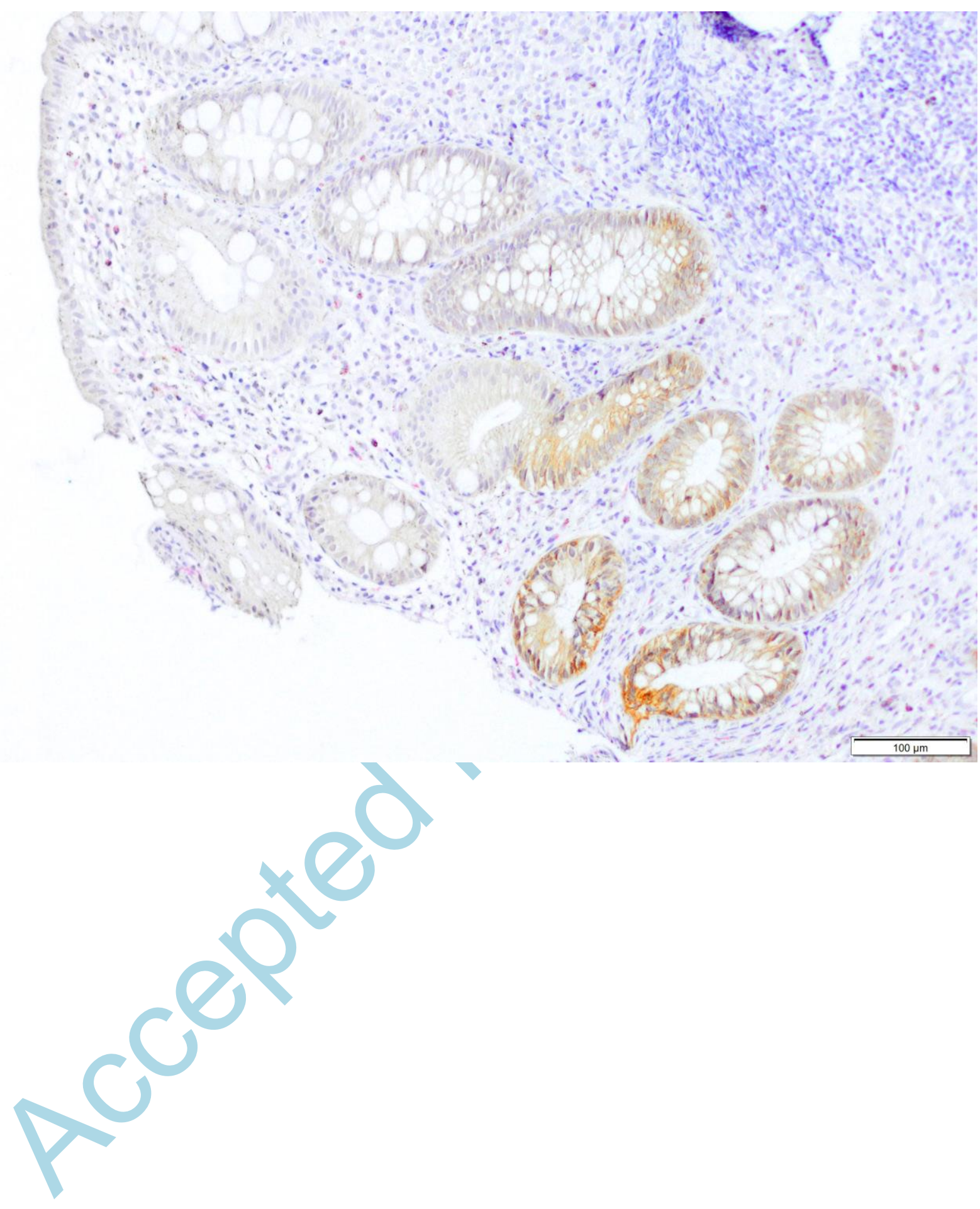